\title{
METAPHORIC TASKS IN PSYCHOTHERAPY: CASE STUDIES OF “MARGIE'S” SELF-IMAGE AND “AMY'S” PAIN
}

\author{
SAM R. HAMBURG ${ }^{\text {a,b }}$ \\ ${ }^{\mathrm{a}}$ Independent Practice; Family Institute at Northwestern University \\ ${ }^{b}$ Correspondence regarding this article should be sent to Sam R. Hamburg, 79 W. Monroe Street, Suite 1311, \\ Chicago IL 60603 \\ Email: samrhamburg@gmail.com
}

\begin{abstract}
Metaphor exists not simply as figurative language but as a fundamental organizing principle of human thought. Given the appropriate context, anything can function metaphorically. In the presently described cases of "Margie" and "Amy," which differed in many ways, a common theme was the effective incorporation of simple tasks, assigned as homework, which were used metaphorically in successful psychotherapy. In Margie's case, the task was not self-consciously conceived as a metaphor by the therapist, but it functioned that way. The therapeutic power of that metaphoric task was confirmed by the client many years later. In the second case, the task was deliberately formulated as a metaphor. Whether this metaphoric task contributed to the case's initially positive outcome is uncertain. To provide background for understanding the integrative psychotherapy model that I bring to these two cases, a statement on my development as a psychotherapist is included as Appendix 1.
\end{abstract}

Key Words: hypnotherapy; chronic pain; metaphor; homework tasks; behavior therapy; self-concept; selfefficacy; integrative therapy; short-term therapy; case studies; clinical case studies

\section{CONTEXT OF THE CASES}

As a full-time practitioner for 37 years, my personal experiences in therapy and the responses of my clients have interacted with my theoretical training to create a model of psychotherapy that combines client-centered, experiential components resonating with Greenberg's (2002) model of emotion-focused therapy together with behavioral, action-oriented, and short-term components. To provide the reader a fuller understanding of my model and how it developed, including the interaction of different perspectives in the practice of psychotherapy, Appendix 1 presents a personal statement of my theoretical and professional history.

An important component of my theoretical approach involves the importance of the role of metaphor. This role is described below in the section on my Guiding Conception. The two case studies to be presented - while seen over 20 years apart at very different periods in my practice history - both illustrate the value of metaphor in psychotherapy. 


\section{THE CLIENTS}

\section{Margie: A Life of Suffering and Feeling “Inferior to Everybody in Every Way”}

Over 20 years ago when I saw her, Margie was a 45 year-old, never-married woman who described her life in terms in terms of unending suffering. Her father, who had been deceased for 20 years, had been an angry, aggressive manual laborer who beat her repeatedly. Her mother, still alive, was kind and well-meaning, but described by Margie as "weak" and non-nurturing.

Margie had worked in the same administrative position in a medium-sized company for many years. There, she had met an older woman, Rose, whom she consciously identified as the strong maternal figure she had never had. They became roommates, Margie moving into Rose's house and paying rent to her.

Margie described a grim existence. She derived no satisfaction from her job. Outside of work, her only social experiences, besides the relationship with Rose, were occasional contacts with women friends. Her main pleasure was impulsive shopping, which had led to a credit debt equivalent to almost two years of her salary.

\section{Amy: Sudden and Then Persisting Physical Pain Out of the Blue}

In many ways, Amy was as different from Margie as could be imagined. Amy was younger, 26, attractive, talented, and successful as an architect She was socially successful, with many friends, and was currently in a romantic relationship with a professional. She was the daughter of two, long-married physicists and had been raised in stable, upper middle-class circumstances.

Amy had been very shy as a little girl and her parents had taken her to a psychotherapist, Rachel, for help, whom she had continued to see up to and during the time I saw Amy. Also, as a child Amy had also suffered from nightmares, and this was a problem that persisted into her adulthood, at a rate of 3-4 nights a week. At the start of therapy she also suffered from early insomnia .

One day about two years before she came to me for therapy, Amy developed a tremendously painful sensation in the lower right quadrant of her abdomen. No known medical cause for the pain had been identified, but it persisted unabated in an up and down fashion, which was highly distressing to Amy and very disruptive of her life. This is what led Amy to come to see me for hypnosis.

\section{GUIDING CONCEPTION}

As mentioned above, my overall theoretical approach to psychotherapy is an integrated combination of experiential and behavioral approaches. The broad nature and background of the development of my approach is detailed in Attachment 1. Moreover, an important component of my model is the use of hypnosis. My guiding conception in using hypnosis is presented in an earlier PCSP case study (Hamburg, 2006, pp. 3-7, doi: http://dx.doi.org/10.14713/pcsp.v2i2.873). 
S.R. Hamburg

Pragmatic Case Studies in Psychotherapy, http://pcsp.libraries.rutgers.edu

Volume 13, Module 4, Article 1, pp. 284-328, 02-24-18 [copyright by author]

My particular approach to hypnotic suggestion is presented in Table 1. Below I focus on one aspect of my approach: the role of metaphor in psychotherapy.

\section{Metaphor}

A variety of claims have been made for the psychotherapeutic power of metaphor: metaphor allows clients and therapists to express what would otherwise be inexpressible, particularly concerning intimate feeling states; allows a more relaxed and collaborative psychotherapeutic atmosphere, especially when the therapist makes use of metaphors introduced by the client; facilitates problem description and resolution by making explicit what had been implicit, especially the client's habitual assumptions and interpretive strategies; and even helps clients identify new possibilities for action (McMullen, 2008).

What all these claims have in common, aside from scant empirical support (McMullen, 2008), is that they are all based on the traditional conception of metaphor as a rhetorical device-as figurative language. In recent decades, a more comprehensive view of metaphor has emerged: that metaphor is not just a way people speak, but a way people think. Indeed, it has been argued that metaphor is fundamental to the creation of cognitive structure. On this view, "[t]he essence of metaphor is understanding and experiencing one kind of thing in terms of another" (Lakoff \& Johnson, 1980). The thing to be understood (the "topic") is generally abstract or complex or ineffable, while the thing by which it is understood (the "vehicle") is comparatively closer to lived, perceived experience. The metaphor posits some similarity between the two things, something they have in common, by which the vehicle conveys a new understanding of the topic.

And since similarity is not a matter of the objective characteristics of things but rather of our purposes and intentions, virtually anything can stand as a metaphor for anything else (Goodman, 1972). Think of the title of the old song, "Life is Just a Bowl of Cherries." The last five words could be replaced by virtually anything- "a game of Pick-Up Sticks," "ebbing and flowing tides," "walking shadow"-and produce an intelligible metaphor. (For "game of PickUp Sticks”: it's a mess, you've got to clean it up, and if you make one false move, you lose.) And because metaphor is a property not just of our language but of our concepts, it can exist in any domain. Consider, for example the last scene of Alfred Hitchcock's North by Northwest in which the image of a train entering a tunnel clearly seems a metaphor for sexual congress.

This report describes two cases in which psychotherapeutic tasks were used metaphorically. In the first case, I was not fully aware of the task's metaphoric nature until long after I had employed it. But it was just that which was of decisive influence in the therapy. And many years later, the client cited that task as the critical event in her therapy. In the second case, the metaphorical nature of the task was fully intended from the outset; and the task was nested in a set of complementary metaphors. However, in this case, as successful in its own way as the first, I am not confident that the metaphoric task was crucial to the positive outcome. 


\section{Concrete Tasks-Metaphoric and Non-Metaphoric}

Concrete tasks are used in some varieties of Western psychotherapy and in diverse nonWestern methods of psychological change, and with good reason: they give the therapist leverage. Instead of waiting for the contingencies of daily life to provide opportunities for learning, or waiting for the gradual development of the therapeutic relationship to yield a corrective emotional experience (Alexander, 1948), the therapist uses concrete tasks to prompt and produce them.

In the behaviorally inspired therapy that I practice, therapeutic tasks usually have a rationale from operant or Pavlovian conditioning, or from both. Having a couple engage in a structured exercise of expressing appreciation is intended both to teach them that skill, and to increase the total rate of positive reinforcement in the relationship. For a client who is phobic, and routinely faints, when receiving injections or having blood drawn, the assignment to watch YouTube videos of these procedures at home is obviously intended at desensitization. Having shy clients introduce themselves to somebody new every day aims at both skill acquisition and anxiety desensitization.

Tasks themselves are neither inherently metaphoric or non-metaphoric. It is the context in which they are presented that renders them one or the other. Jigsaw puzzles, for example, used metaphorically in Margie's case below, can be used non-metaphorically, within a straightforward exposure with response-prevention framework, to treat obsessiveness. By obsessiveness, I mean not classic obsessive-compulsive behavior but the obsessiveness of the achievement-oriented workaholic who comes home late from the office only to say to the family that there is just one more little work item to complete before dinner-and then is never heard from again. For such people, the jigsaw puzzle is used as a lesson in letting go. The effectiveness of the jigsaw puzzle in this application hinges on the fact that for an obsessive anything, no matter how trivial, is important once it becomes the focus of attention. The instructions for the task are:

What I want you to do is get hold of a jigsaw puzzle — 500 pieces, 1000 pieces — and set it up on a table somewhere. Then, you work on it every day for 10 minutes and only 10 minutes. Use the timer on your cell phone or the time-down function on the runner's watch you're wearing. As soon as it times out, you stop working on the puzzle and walk away. Even if you're holding a piece in your hand and you know exactly where it goes, you drop it and walk away.

In subsequent sessions, the therapist helps the client process their experience of the task. Most often, obsessive clients initially can't help cheating, lingering at the puzzle for a few minutes — or many minutes - after their time is up. But they are remarkably honest with the therapist about this. By helping the client focus on the experience of leaving the puzzle, the therapist can help the client get to the point where leaving it is accompanied by a feeling of liberation rather than frustration. The next step is to help the client examine whether other more "important" tasks are, in fact, more like the puzzle than unlike it in their susceptibility to being interrupted. 
Metaphoric tasks, by contrast, are learned and practiced not for their own sake to achieve some conditioning or learning objective, but because they point to something else- - something much larger than the task itself. There is a certain beauty in finding a small task that is paradigmatic of a person's larger struggles and have its effects reverberate out to those struggles.

The quintessential metaphoric task is the Zen task. The Zen acolyte takes up the study of flower arranging or archery not to become adept at interior design or hitting a target, but rather through these practices to acquire understanding of the truths of Zen. These truths, when reduced to words, can sound paradoxical or even nonsensical; but they can be experienced via learning the skill. And conversely, the skill can be perfected only by gaining sight of and surrendering to those truths. In the Zen practice of archery, the correct technique of releasing the bowstring cannot be learned with out a Zen understanding of "loosing oneself" — which can be learned only by repeated practice of releasing the bowstring. But always, acquisition of the skill is secondary to acquisition of the understanding (Herrigel, 1953).

Compared to flower arranging and archery, the tasks in the cases presented here are simple, trivial even: assembling a jigsaw puzzle, and tapping the hands and feet according to a prescribed pattern. Yet they, like the Zen tasks, were intended to point to something larger than themselves.

\section{A.-8A. ${ }^{1}$ MARGIE'S THERAPY: JIGSAW PUZZLE AS METAPHOR FOR AN ENTIRE LIFE}

\section{A. Assessment of Margie’s Problems, Goals, Strengths, and History}

At the beginning of our therapy, over 20 years ago, Margie was a 45 year-old, never married woman who described her life in terms of unremitting misery and failure. Her fatherby this time, dead 20 years-a brutish, alcoholic, improvident construction laborer, beat her, her younger brother and sister, and her mother repeatedly and mercilessly. He was also verbally abusive, disparaging Margie as "ugly” and "stupid.” (Although over 200 pounds at the time of treatment, Margie reported that she had been half that weight in high school, and had been regarded as pretty by others in her childhood and youth. My own estimate of Margie's intelligence was that she was above average.) Her mother, still alive, was kind and well meaning but "weak"; and Margie had never experienced much nurturance or support from her. She described her relationship with her mother, now happily remarried, as good.

The most significant event in Margie's youth was a two-year relationship with Tommy, a young man from a well-to-do family on the better side of town. The relationship was stormyeach cheated on the other-and when Tommy went off to Vietnam, Margie took up with another young man, known in the community as a criminal. Tommy returned from Vietnam, and

\footnotetext{
${ }^{1}$ The next eight sections are numbered 4A-8A,and 4B-8B, respectively, to indicate their parallel to sections 4-8 of a typical pragmatic case study (Fishman, 2013) —specifically: 4) Assessment of the Client's Problems, Goals, Strengths, and History; 5) Formulation and Treatment Plan; 6) Course of Therapy; 7) Therapy Monitoring and Use of Feedback Information; and 8) Concluding Evaluation of the Therapy's Process and Outcome. Sections 4A-8A describe Margie's therapy, and sections 4B-8B, Amy's therapy.
} 
evidently having learned while still overseas of Margie's infidelity, spurned her and married someone else. For ever after, Margie blamed herself not only for Tommy's rejection of her but also for the heroin addiction he had acquired in Vietnam. During the more than two decades since, Margie cultivated an elaborate fantasy life centered around Tommy, visualizing him treating her affectionately and making love to her. Her overt romantic life, over that same period, was close to non-existent: three brief dating relationships that never became serious.

Margie had worked in the same administrative position in a medium-sized company for many years. There, she had met an older woman, Rose, whom she consciously identified as the strong maternal figure she had never had. They became roommates, Margie moving into Rose's house and paying rent to her. Rose drove Margie to her first few appointments with me because Margie was afraid she would get lost somehow if she tried to drive to my office herself.

Margie described a grim existence. Her job was uninteresting and-ever since her company had been taken over a few years before, and her workload increased-difficult and anxiety provoking. She constantly needed to seek help from her supervisor. This was humiliating to Margie and further strengthened her abiding sense of incompetence. Outside of work, she socialized occasionally with women friends and shopped. Shopping was Margie's major leisure time occupation; she had no other hobbies except for growing flowers in the backyard in the summertime. For Margie, shopping was both a way to feel smart and effective and a way to make up for what she had never had in her impoverished childhood. By the time of treatment, she had accumulated credit card debt equivalent to almost two years' salary. Margie was very ashamed of this, and it took her several sessions to reveal it to me.

Margie had been in insight-oriented therapy episodically over 15 years with two female therapists, and had experienced no discernable benefit aside from a transient feeling of catharsis after the sessions. Telling Margie that she might benefit from a male therapist, her personal physician referred her to me. (He knew that my approach was also quite different: an integrative amalgam that is about equal parts experiential [Greenberg, 2002] and behavioral--actionoriented, and short-term.) By the time of the referral, Margie had been medicated for some time with a $75 \mathrm{mg}$ daily dose of Zoloft. This, according to her, had brightened her mood somewhat but had not affected her self-concept or overt behavior. Margie felt like a complete failure. Her past had been a catastrophe. And in the future she would never have the things she most wanted: love, a husband, a daughter of her own. Her life was "over."

\section{A. Margie's Formulation and Treatment Plan}

It is easy to attribute Margie's adult miseries to the terrible adversity in her childhood; in particular to the demeaning treatment at the hands of her father as the origin of her negative self concept. The picture must be more complicated though. First of all, we know that the rule among children is resilience (Hamburg, 1998). The vast majority who experience terrible childhood adversity grow up to be well functioning, mentally healthy adults. So we are left with the surmise that she must have inherited a temperament that made her unusually vulnerable. And presumably, a pattern of social aversion and isolation after being spurned by Tommy prevented her from meeting a man whose romantic affirmation might have repaired her horribly negative 
self-concept. The objective of therapy would be somehow to get her to believe that she was someone other than the person that her life so far had convinced her she was.

\section{A. The Course of Margie's Therapy}

\section{Sessions 1-6. Not Much Progress}

Faced with a life so unfortunate it is easy to feel overwhelmed, if only by the sadness of it all. And then there is the question of how to intervene, where to start: as if there were a large boulder before you which you must move with a crowbar, and you circle around it looking for a place where you might gain purchase.

The first few sessions were pretty ad hoc. At the end of the first session, in view of Margie's manifest depression, I recommended that she start reading Learned Optimism (Seligman, 1990). The other obviously justified recommendation was that she attend meetings of Adult Children of Alcoholics (ACOA). (In the event, despite prompting over several sessions, Margie refused to attend ACOA. She was certain that thinking, and talking in ACOA meetings, about her childhood would be "just another type of torture.”) The second session, like the first, was mostly past-oriented, centering on her father and Tommy. At the end of it, I suggested that she write a cathartic letter to her father, telling him how her life had gone since his death, and how she felt about his treatment of her and its consequences. She brought the beginning of the letter to the fourth session. It was long, filled with hate, and she was glad she had written it. During that session, the focus shifted from hatred of her father to self-hatred. I observed that, ironically, she was being loyal to her father by berating herself in the same terms as he had. She did not like the sound of that. I asked her to write a list of her father's disparagements of her and a list of her own and compare them. At the next session, Margie expressed shock at the similarity of the two lists: "I'm appalled...It's him again." At the end of the session, I asked her, when she noticed that she was putting herself down, to close her eyes and visualize her father saying those same things to her. Clearly, by that fifth session the focus was shifting from the past to the present and narrowing to Margie’s negative self-concept.

The sixth session continued in the same vein, this time focusing on her sense of being physically ugly. I did not adequately think through my suggestion that she confront her physical self in a mirror (Mahoney, 1991) and it backfired: she was so depressed the day after the mirror exercise that she couldn't go to work.

\section{Sessions 7-9. Introduction of the Jigsaw Puzzle Task}

In the latter part of the seventh session, Margie returned to the theme of being "inferior to everybody in every way." She mentioned, in that regard, that she had never learned to skate or ride a bicycle. Making the connection with those activities, I recalled that some time earlier Margie had mentioned that she had tried to use Rose's NordicTrack machine, but couldn't learn how to use it. Having had experience with that machine, I asked Margie how long at a time she had spent trying to learn it. She said that she had stayed on the machine for maybe a minute at a time. I replied that the instruction booklet said that it took 10 minutes to learn, and that was 
indeed how long it would take. I instructed her to get on the machine and not get off it for 10 minutes, and I guaranteed that at the end of the 10 minutes she would get it.

Then, as an afterthought, perhaps to complement the physical with the mental, I suggested that she go out and get a 500-piece jigsaw puzzle and spend 10 minutes a night putting it together. Margie insisted that she could never do that. I insisted that she could and gave her some general instructions on how to begin (i.e. decide what sector of the puzzle you will start with, isolate the pieces of that general color, find the edge pieces and put them together first). Having worked in inpatient settings, I had seen psychotics and deteriorated alcoholics assemble jigsaw puzzles. Anyone can assemble a jigsaw puzzle_-although it would have been a mistake to put it to her that way. I was hoping that assembling the puzzle would be an object lesson: that it would teach her that she was smarter than she thought - that she could do things that she thought she was too stupid to do.

At the eighth session, Margie reported that it had taken her only six and a half minutes to learn the NordicTrack but that working on the puzzle 10 minutes per night, she had not been able to put even a single pair of pieces together. It dawned on me only then that, while the 10-minute limit made sense for obsessives, it was arbitrary and much too short in this case. So I suggested that Margie spend 20 minutes per night on the puzzle. That would be long enough to get something done, but not so long as to be tiring or oppressive. At the next session, though, Margie reported that she hadn't tried to assemble the puzzle at all—had done no more than look at it. (It should be noted that between the eighth and ninth sessions Margie's doctor raised the dose of Zoloft from $75 \mathrm{mg}$ to $100 \mathrm{mg}$. This was not done at my suggestion.) I asked Margie to bring the puzzle with her the next time we met.

\section{$\underline{\text { Session 10. Bringing the Puzzle to the Session }}$}

Margie did bring the puzzle to the tenth session. It was the usual dime store jigsaw puzzle: pretty flowers in the foreground, a quaint cottage further back, trees, blue sky with fluffy clouds. The entire session was devoted to the puzzle. As soon as Margie walked into the consulting room, I invited her to sit on the floor with me. She did so, muttering, "This is stupid...this is ridiculous...I can’t do this...I don't want to do this,” a litany that she continued for many minutes. I helped her spread the pieces out and turn them right side up, since these acts were mechanical and not germane to solving the puzzle. Once the pieces were all laid out, ready to be assembled, Margie just sat there, the picture of inertia. This was no time to explore her resistance; the reasons for it were clear. What was needed was prompting. I told her to choose an area of the puzzle, isolate those pieces, and pick out the edge pieces, all of which she did, muttering all the way. Sometimes I responded to her negative mutterings-gently, cajolingly, "It's not stupid...it’s important...you can do it...come on, please play along with me on this," sometimes not.

Finally, the most unwelcome prompt: “OK, now start to put them together.” Margie picked up two pieces, barely touched them to each other, and threw them back on the pile, muttering incessantly that this was stupid, impossible, that she could never do this. She picked up two more pieces, barely touched them to each other, threw them down, and then repeated this routine with several other pairs of pieces until I stopped her: "Hold it. You're not giving 
yourself a chance. You're so convinced you can’t do it that you're hardly trying.” Margie acknowledged that this was true.

I then told her to try to fit each pair of pieces together in all possible rotations, to discard only one of the pieces if they didn't fit, and to put the discarded pieces off to one side so she would know which ones she had tried. (I didn’t pick up any pieces, didn't demonstrate, just told her what to do.) She did all these things and eventually, inevitably, she fit two pieces together. She was amazed and obviously pleased. With minimal prompting, she put together another six or eight pieces in the next several minutes. Her astonishment was undiminished; the contradiction between her self-expectations and performance was so stark.

In the last minutes of the session I suggested that maybe she approached other things in her life she "couldn't do" in the same way that she had initially approached the puzzle: so convinced she couldn't do the task that she didn't really make contact with it, for example skimming a memo from her supervisor and then concluding that she couldn't understand it, instead of reading through it carefully, several times if necessary. At the end of the session, Margie agreed to continue working on the puzzle at home.

\section{$\underline{\text { Session 11-16. Consolidating Gains }}$}

Margie made slow but steady progress over the next six sessions. At the 11th session, she reported that she had assembled more of the puzzle and enjoyed it. At the $12^{\text {th }}$, she reported that she was close to finishing it, tended to do it when she felt down, and intended to buy another one. At the 13th, she reported that it had taken her all day to figure out an assignment her supervisor had given her but that she finally succeeded without having to seek assistance.

At the $14^{\text {th }}$ session, Margie reported that she had mailed out two applications to do volunteer work, something she had long contemplated doing but could never get herself to do. And she had completed an application for assistance from a consumer counseling service. She also stated that she was amazed that she was "really looking forward" to learning Lotus and WordPerfect on Rose’s new personal computer.

By the $15^{\text {th }}$ session, she had signed up, along with Rose, for a course on Windows; and had begun teaching herself needlepoint, which she found easier than expected.

By the sixteenth session, which took place a month later, Margie had mailed the application for credit counseling, finally overcoming the fear of humiliation that had blocked her from mailing it earlier. Also she reported that, observing her coworkers during a staff meeting, she had come to the realization that it really wasn't true that she was stupid and they were all smart. "I'm like everybody else, and I never thought I was."

\section{7a. Therapy Monitoring and Use of Feedback Information}

No formal monitoring of the therapy was conducted other than the processes described in the above section. 


\section{8a. Concluding Evaluation of the Process and Outcome of Margie's Therapy}

\section{Interpreting the Positive Changes in Margie’s Behavior}

I did not employ standardized measures of change to evaluate Margie's behavior. However, the positive behavioral changes documented by the end of therapy and her conclusion that "I'm like everybody else, and I never thought I was" are strong indicators of success in her therapy.

In explaining this success, it should be noted that Margie's in-session puzzle encounter occurred as part of a psychotherapy whose most important events are conceived as occurring outside the consulting room, as homework. The outcome of one homework task, as discussed in the session, leads to hypotheses that inspire the next homework, and this dialectic sets the direction of therapy. Had Margie succeeded in assembling the puzzle on her first or second try, this crucial event, too, would have occurred outside the consulting room.

Individual case studies do not, of course, permit strong conclusions about causality (Campbell \& Stanley, 1966). I cannot say for certain that the strides Margie made after initially succeeding in doing the puzzle were, to any significant extent, caused by that event-although that is what I believe. They may have been caused by non-specifics of the evolving therapeutic relationship, by influences from some of the earlier homework assignments, by something she read in Learned Optimism, or by the Zoloft or some other factor extrinsic to therapy. (Or, instead of a strong listening-to-Zoloft hypothesis, a weak one: that the increased dose produced a state of readiness or receptivity without which psychotherapeutic interventions would have been fruitless.)

Or if, indeed, some of the positive changes were produced by the experience of doing the puzzle, it cannot be said for certain what about doing the puzzle was crucial to the changes. Was it simply demonstrating to herself that she could do something she had always thought impossible for her?

Or was it the fact that, during her eventually successful attempt, a male figure whom she defined as older, intelligent, and accomplished, was sitting by her side, encouraging her and having faith in her-being very different than her father had ever been with her?

Or might she have been better off if she had succeeded in assembling the puzzle at home because then she would not be tempted to point to my encouragement and coaching as factors in her success?

Post-hoc interpretations are the easy part of psychotherapy. Therapists of different persuasions can no doubt invent many to supplement the few offered here. What I do know for certain is that the puzzle yielded an experience that was illuminating and instructive for both client and therapist. For that reason, if for no other, it was of value. 


\section{Post-Script. Twenty-Two Year Follow Up}

One day in early 2016, in search of a FedEx shipping label, I opened the cabinet beneath the bookshelves in my consulting room. I found the label, but was appalled by the clotted mess in the cabinet. Then and there I decided to purge it. Among the accumulated junk I pulled out was a 9 x 12 envelope with the inscription, "7-26-95 mailed to [the name of a clinical psychology journal].” Inside the envelope was the case report on Margie (reproduced here with only minor changes). I was astonished; I had no recollection of having written it. If the manuscript had been rejected, I would have remembered it. I surmise that it got lost, either in the mail or in the journal's shuffle. Preoccupied as I had been, at the time, with starting a new practice from scratch at mid-career in a strange city, I simply forgot about it. When I discovered it and saw the title, I presumed the paper would describe the application of puzzles to obsessionality, as the first part indeed does; I had used puzzles in this way with several patients during my 20 years in Chicago. I was not prepared for the story of Margie; I had never again used a puzzle that way.

At first I could not remember who the patient was. But then when the credit card debt was mentioned, her identity came back to me. I remembered what she looked like, her voice, and who had referred her. She was one of the last patients I saw in my New Jersey practice before closing it in late 1994. I remembered that I had cautioned her about starting therapy with me because I would be leaving the state in just a few months. She insisted on trying, nevertheless, because her doctor, in whom she had great trust, had recommended me. I didn't remember Margie's real name until the next day; I vaguely sensed that it was very similar to that of a famous actor, differing in only a couple of letters - and then I got it. What I remembered about the therapy was that the client had had a difficult and unhappy life, that we were able to complete our work together in the time we had, and that it had been reasonably successful. I remembered nothing about the puzzle. It struck me as the kind of thing I would have tried; I just didn’t remember trying it.

I often have been curious, sometimes intensely, about the fate of my former clients. Occasionally, that curiosity has been satisfied by an unsolicited letter or phone call. But I have never inquired. In my view, mere curiosity is never sufficient justification for a therapist's question. The question must have a therapy-related purpose. I felt there was justification to follow up with Margie: A therapist had used a specific technique with a client, and attributed much of his therapeutic success to the use of it. Yet, years later he didn't remember having used it then, and had not used it with any subsequent client. If the client, many years later, regarded the therapy as having been helpful, to what did she attribute that - the technique or something else? Did she even remember the technique, or had she, like the therapist, forgotten all about it?

My prediction was that non-specifics would trump technique- that Margie would have also forgotten the puzzle and would attribute whatever benefit she felt from therapy to my having been kind to her. I very much wanted to find out if I was right about the non-specifics as the factor that made the lasting impression, so I consulted with a trusted colleague about the ethics of intruding into a client's life after so many years. We decided that the safest course would be to ask the physician who had referred her, and with whom I had maintained a friendship, to call 
Margie and ask if she'd welcome a call from me. The doctor returned with the news that indeed she would.

My call went to voicemail, but Margie returned it within a couple of hours. She sounded happy to be speaking with me. First, I asked her about her current medical problems, which her internist had mentioned to me, and we discussed them in some detail. Then I explained my reason for wanting to speak with her: that I had found something I had written 21 years ago about our work together; that I had no recollection of ever having written it; and that it was about something that occurred in our therapy that I had felt to be important back then, but that I also had no recollection of. I asked her, "Can you remember anything about the therapy that was particularly helpful?”

The first thing she said in reply was, "You had a very calming way about you...your voice." The second thing she said was "We were on the floor doing a puzzle." Then she said "You had a lot of compassion...you changed my life is what you did." After that she said "Your voice is very soft and caring." After that she reminded me that she had tried other therapists before me but they hadn't done her any good; and that at first she was skeptical about me, but when I mentioned that I was a short-term therapist who tried to finish therapy inside of 20 sessions, and certainly less than a year, she was heartened. After that, she returned to the puzzle: "I had no patience, and as we did it, you told me what my thought process was." Two things about that sentence struck me: she said "we" instead of "I," even though it was only she who was doing the puzzle; second, that she had some recollection of my giving her a running commentary on her ongoing experiential flow. When I wrote the case report, I evidently didn't remember anything like that, but I can imagine having said things like "You're being impatient because you're so sure you can't do it-but you can do it."

She seemed to have nothing more to say about the puzzle so I changed the subject to her life over the past 22 years. In major ways, it continued as it had before the therapy: same job for 17 of those years, same living arrangements with Rose. There had been a struggle with cancer during which she found inner strength that she had not known she had. On the positive side, in her new job she was working with children, which she greatly enjoyed; she and Rose had bought a house in a pretty little town in rural New Jersey; and she had nice friends. She summed up by saying, "I have nice friends, I have a nice life. I'm glad to be alive."

In the subjective interplay of psychotherapy, it is often difficult to know the client's interpretation of what the therapist says and does. What seems significant to the therapist is often not perceived as such by the client. A client says, "Something you said last time was so important to me...made such a difference." You think you know the pearl of wisdom the client is referring to- and then they quote back to you not that gem but something you don't remember having said. This has happened to all of us countless times. In this instance, though, an item of technique that was salient to the therapist at the time of treatment was salient in the client's memory of the treatment many years later. But it is not as simple as that. The memory of the technique was embedded in the client's memory of the non-specifics—-"You had a caring way about you...," "You had a lot of compassion." And indeed, what to me was an important, specific, element of the "non-specifics" was an essential element of her memory of the 
technique: "we were on the floor doing a puzzle.” Although I cannot prove it, I strongly believe that the puzzle would not have worked for her if I had remained in my chair while she sat on the floor with it. It might not even have worked if we had been sitting around a table with the puzzle laid out on it. By sitting on the floor with her, I believe that I changed in her perception from authority figure to a comforting blend of peer and parent, thereby providing a safe emotional atmosphere in which she could risk feeling incompetent and inferior. I sensed then, what I know now: technique is inextricable from relationship.

But what was it about this particular technique that made it so powerful at the time, and made it salient, many years later, in her memory of the entire therapy encounter? I believe it was the metaphoric power of the puzzle. For Margie, the puzzle-as something she was convinced she absolutely could not do-encompassed all the different ways she had been stupid, incompetent, and inferior all her life. Discovering that she could do the puzzle put the lie to much of her negative self-concept and forced her to rethink it. I was thinking of object lessons, not metaphors, when I assigned the puzzle. I now understand that object lessons are metaphors.

\section{B-8B. AMY'S THERAPY: EMBEDDED METAPHORS IN THE TREATMENT OF A CASE OF CHRONIC PAIN}

\section{B. Assessment of Amy's Problems, Goals, Strengths, and History}

In many ways, Amy was as different from Margie as could be imagined. She was much younger, 26; talented and successful, an architect who had advanced in her profession with remarkable speed; and she was blessed with strikingly good looks. She was successful in her interpersonal relations, with many friends; and she was currently in a romantic relationship with a structural engineer. She was the daughter of two, long-married physicists and had been raised in stable, upper middle-class circumstances. As unlucky as Margie had been in life, Amy had been lucky. Amy's manner was accordingly cheerful and positive. She said that her current life, overall, was "pretty great."

Her life had not been all hearts and flowers, though. Amy perceived herself as less favored by her parents compared to her younger brother who, like them, was a physicist. (In her family, Amy, a highly intelligent and technically trained person, was considered "the artsy one.") Amy's sense of her parents was that they were supportive and caring, but on balance critical. (Nonetheless, she remained in fairly close contact with her parents especially since the onset of her pain. Amy's mother accompanied her to my office for the initial interview-but did not sit in-presumably to check me out.)

Amy had been very shy as a little girl and her parents had taken her to a psychotherapist, Rachel, for help. From then onward, up to and including the time Amy and I worked together, she'd continued in a treatment relationship with Rachel. At one point, after Amy and I had worked together for several months and achieved substantial results, she mentioned in passing that there were only three people in the world whom she entirely trusted: her parents and Rachel. (Amy gave me permission to speak with Rachel and I tried a couple of times, but she never 
S.R. Hamburg

Pragmatic Case Studies in Psychotherapy, http://pcsp.libraries.rutgers.edu

Volume 13, Module 4, Article 1, pp. 284-328, 02-24-18 [copyright by author]

returned my calls. I didn't persist because my understanding was that she had not played a significant role in the attempts to relieve Amy’s pain.)

In childhood, Amy had also suffered from nightmares, and this was a problem that persisted into her adulthood, at a rate of 3-4 nights a week. They generally had the same content: either being chased, or being trapped in a room filled with bugs, and then the room being flooded with water and the water being filled with the bugs. The nightmares almost always woke her up, causing middle insomnia. She could generally get herself back to sleep after reading for a while. Currently she also suffered from early insomnia. About a year after the onset of the pain, a psychiatrist had prescribed escitalopram, a selective serotonin reuptake inhibitor (SSRI) directed towards reducing anxiety and depression, initially at $5 \mathrm{mg}$, now at 7.5 mg, for Amy's “anxiety.” It did not mitigate the nightmares or otherwise improve Amy’s sleep, and it had no effect on the pain.

Amy's pain had come on suddenly one day a little more than two years before we met. She was at the office, working at her drafting table, when all at once, she felt an overwhelmingly painful sensation in the lower right quadrant of her abdomen. The pain doubled her over and she vomited. She hadn't felt unwell in any way at all before that moment; the pain had the most acute onset imaginable.

The first thought, of course, was appendicitis, but it didn't turn out to be that. And to make a very long story short, it didn't turn out to be anything that could be diagnosed medically. A physician friend of her family's had conducted her through a procession of medical specialists, who, despite a wide variety of tests and imagings, could not identify a physical cause for Amy's pain. Finally, Amy was taken to an obstetrician-gynecologist, who had referred to me in the past and knew I used hypnosis-and so Amy got to me.

Amy reported that the pain varied little from day to day, or over the course of a single day. It was generally between 7.5 and 8 on a conventional 10-point rating scale. Early on she had been prescribed tramadol. By the time we met she was taking one or one and a half $50 \mathrm{mg}$ tablets four to six times every day. Even with this large dose of medicine, the pain never got lower than 4. She could discern no pattern to the pain; its severity seemed to vary randomly. If the pain did subside slightly for a brief period, she knew it would come "roaring back." (Initially, the drug had made her feel drowsy and headachy, but in time these side effects abated, and now she was troubled mainly by dry mouth.)

Occasionally there would be a day when the pain was so severe that the only thing Amy could think to do was go to the ER; the last such day had been about 5 months before we met. The pain affected her life in a variety of ways. Most troubling was when it caused her to have to cancel out on social plans she had made. And ever since the day the pain began Amy had been unable to sleep on her right side, heretofore her preferred position for sleep. In addition, the pain caused her to be reluctant to consider job offers outside of Chicago; she felt she needed to be in close proximity to her parents in case of some pain-related emergency. 
S.R. Hamburg

Pragmatic Case Studies in Psychotherapy, http://pcsp.libraries.rutgers.edu

Volume 13, Module 4, Article 1, pp. 284-328, 02-24-18 [copyright by author]

At one point in her initial presentation, Amy became tearful for no obvious reason. I inquired what was behind the tears. She thought for a moment and then replied that she was afraid to hope that I might be able to help her.

\section{B. Amy's Formulation and Treatment Plan}

It would have been easy to conclude that Amy's pain was psychogenic; after all no physical cause had been found. Perhaps it had to do, in some complicated way, with her ambivalence toward her parents and the mutual hostility between her and her brother; or with her feelings about being a woman in what was still a male-dominated profession.

But I didn't want to formulate the case that way, for a number of reasons. First, I could not make up a credible story of how/why that particular symptom, the pain, occurring at that particular point in her life, could have functioned as an expression of, or resolution to, those sorts of conflicts. I could not discern any "secondary gain” from it-any way in which it solved some emotional problem for her.

Second, to label the pain as psychogenic would have ruled out hypnosis, since hypnosis is ineffective in psychogenic pain (Chaves, 1993) — and I wanted to do hypnosis. Before I even met her, based on my initial phone conversation with Amy, I'd thought of a way of going about it.

Third, I felt that formulating the pain as psychogenic would be heard by Amy as blaming the victim-dispiriting and maybe even insulting. (And although it appeared that none of the previous doctors had said it to her outright, I suspected that the message had been conveyed to her somehow.)

Fourth, just because a physical cause for the pain hadn’t been found didn’t mean there wasn't one.

And fifth, my clinical experience has led me to conclude that for me, psychodynamic formulations have not been pragmatically effective in facilitating positive change.

My working hypothesis was this: There was a physical cause for Amy's pain. Some transient perturbation — an allergy, a virus, some mechanical strain, something else — set it off. The perturbation passed, but caused a problem in Amy's pain-signaling system — a neurological problem - that prevented the pain, which itself should have been transient, from turning off. (We all get a stitch in our side occasionally. We don't think of it as being psychogenic. What if you got a stitch in your side and it never went away?)

Whatever the neurological anomaly was, it could easily be small enough to be undetectable by existing medical technology. Since hypnosis works via mechanisms of attention, and we know these mechanisms are implicated in the experience of pain, it might be possible to disrupt the pain signaling via hypnosis. 
Regarding my treatment plan, because one’s own experience of pain cannot be directly experienced by others, we must use metaphor just to describe it: sharp, dull, burning, throbbing, etc. Not surprisingly, then, hypnotherapy for pain makes extensive use of metaphor. This begins with the term of art used to describe the treatment to clients: "reprogramming your nervous system.” Hypnosis as "reprogramming” is easily accepted given the widespread (mis)understanding of the brain as being a sort of computer. The IT metaphor enables hypnotherapy to seem more feasible - we all know that we can program and reprogram computers - and less mysterious than it might have otherwise. And once the reprogramming metaphor has been established, any other task can be assimilated to it and perceived by the client as part of the hypnotherapy. This was the strategy employed with Amy.

\section{B. The Course of Amy's Therapy}

\section{$\underline{\text { Session } 1}$}

The first step in the treatment was to present this formulation to Amy and assure that she accepted it. Toward the end of the first session I said to Amy that in order to work together on her pain we had to agree on what it was. I then asked her, "What is pain... why do we have it?" She paused and then answered in an uncertain tone, "Damage?" I was astonished that this intelligent woman who had been interacting with doctors and therapists about her pain for two years could not concisely answer that pain was an alarm system signaling to us that something was wrong, perhaps dangerously wrong. I gave her this definition of pain and then continued approximately as follows:

Now think about a car alarm. It's there to tell you that some bad guy is trying to get in your car, maybe to steal it. But some kids could be playing football on the street and the ball could hit the car and set off the alarm. Since the ball didn't cause any real harm to the car, we would consider it a false alarm. Nowadays, by law, car alarms are designed to turn off after a minute or two.

But there was a time when a car alarm would keep on sounding until somebody came and turned it off. Whatever turned your pain on was the equivalent of the football hitting the car-nothing very serious, that's why you have no medical diagnosis_-but it did something to your pain signaling system that prevented it from turning off as it should have.

I then explained hypnosis to her and how we might use it to help with her pain. I asked her to read an article of mine on it that had been published in this journal about ten years earlier (Hamburg, 2006) in order learn more about hypnosis and get a better sense of how I use it.

\section{$\underline{\text { Session } 2}$}

The second appointment took place four days later. It began with continued inquiry into Amy's sleep. She generally had early insomnia, lasting as long as an hour, in addition to the middle insomnia. The pain used to wake her up in the middle of the night but didn't anymore. She'd been a poor sleeper since childhood. I gave her my usual set of instructions on sleep 
S.R. Hamburg

Pragmatic Case Studies in Psychotherapy, http://pcsp.libraries.rutgers.edu

Volume 13, Module 4, Article 1, pp. 284-328, 02-24-18 [copyright by author]

hygiene and managing insomnia (e.g., http://www.sleepeducation.org/essentials-in-sleep/healthysleep-habits), and then returned to the pain. She described it as a sharp, stabbing pain.

I handed her a multiplex Swiss army knife and asked her which blade would produce that kind of sensation. She chose not the main knife blade but the awl blade. The area, on the lower right, was five to six inches in diameter. I asked her to describe it in 3-D; she said it would be about the size and shape of her fist. She thought of it as some little creature in there. I asked her if she experienced the pain as hot or cold. She replied that it was neither and added, in passing, that she'd tried acupuncture and cupping treatments which had been ineffective.

The latter part of the session was devoted to recording a hypnotic relaxation induction I adapted from one created by Joseph Barber. It is a "permissive" non-authoritarian induction that invites the subject to enter a hypnotic state rather than ordering them into it. It is time consuming, taking about 20 minutes. After a person has listened to it several times, subsequent inductions in my office can be truncated to 10 minutes or less.

Hypnosis for pain is a crapshoot. If you are lucky and the client has a high level of hypnotic ability, substantial effects can be achieved. If not, hypnosis is unlikely to be effective. We lucked out; Amy turned out to be a wonderful hypnotic subject. She entered into a trance state quickly, and afterwards she reported much more elaborate imagery than I had used. I was elated. This level of imaginative involvement augured well for our further hypnotic work together. I asked Amy to listen to the recording we had made in the session once a day in the morning when she was wide awake. I also suggested that she might try it, at very low volume, to help her get to sleep at night.

In acute pain, hypnosis can yield symptom reduction, sometimes to the point of eradication, by means of simple, direct suggestions (Hilgard \& Hilgard, 1994). Such results are not to be expected in chronic pain (Patterson, 2010). What was needed for Amy was a hypnotherapeutic approach that was indirect and that allowed her to divert her attention away from the pain gradually at whatever pace she could manage. Also I was looking for something Amy could actually do to potentiate the effects of the hypnosis, and also to feel that she was more of an active agent in her treatment. Of course, over her two years of pain she had done many things in her effort to control it, like seeing doctors and taking pills. However ineffective they were, these actions were direct attempts at pain alleviation. I wanted whatever she did now, in an effort to potentiate the hypnosis, to be indirect and not, on the face of it, a pain alleviation behavior. These considerations motivated my choice of treatment approach in our third session, the key session in Amy's course of therapy.

\section{Session 3}

The third session took place nine days after the second. Amy had listened to the hypnosis induction recording almost every day and had used it on a couple of nights to help her get to sleep. She thought it helped.

Using a Digital Metronome. I invited Amy to join me in front of my computer, where a digital metronome was displayed on the screen. Amy was familiar with metronomes, having 
downloaded one onto her phone to help her learn to play the guitar. I set the metronome to 300 beats per minute (bpm) and had her listen to it. Then I set it to $301 \mathrm{bpm}$ and asked her if she could tell the difference between that and 300. Of course, she couldn't because the difference, about $1 / 5^{\text {th }}$ of a second, was far below the just noticeable difference for tempo.

Then I set it back to $300 \mathrm{bpm}$ for a few seconds and then to 299. She could not perceive that difference either, of course. I pointed out that even though we couldn't tell that it was slower we knew that it was. I proceeded downwards in this manner to $280 \mathrm{bpm}$, one bpm at a time. None of the 1-bpm changes was perceptible. I then switched back up to $300 \mathrm{bpm}$; she could hear the difference between that and 280. I then told her that from now on we would be rating her pain on a 300-point scale, and asked her what her current pain was. She said it was pretty bad, maybe 285.

I then told her that we would be using the method of making perceivable changes in imperceptibly small steps to help her reprogram her nervous system so that she could learn to control her pain, and that I would give her a demonstration of that right now. I took out a pair of drumsticks and a rubber practice pad, set the metronome to $150 \mathrm{bpm}$ and played several repetitions of a rudimentary drum pattern (onomatopoetically called the "paradiddle"; L=left, $\mathrm{R}=$ right): L R L L R L R R. I had previously determined that playing $16^{\text {th }}$ notes at that tempo, my performance would be a bit ragged.

And indeed Amy could hear that it was. Then I set the metronome down to $130 \mathrm{bpm}$, a tempo at which I could play the pattern perfectly. Then I set the metronome to $131 \mathrm{bpm}$, itself imperceptibly faster than 130, and said to Amy, "Well, if I can play it at 130, I can play it at 131,” which indeed I could. I proceeded this way, 1 bpm at a time, until I could play the pattern perfectly at $150 \mathrm{bpm}$. (Musicians can learn to play almost anything at a fast tempo by this method, if they have the patience.) As she went back to sit on the couch, Amy spontaneously said that she found all this fascinating.

Hypnosis for Amy's Pain. I then told Amy that now we were going to hypnotize her for the pain, using this idea in the hypnotic suggestion. The transcript of that hypnosis is listed in Table 2, consisting of Parts A-E.

Because Amy was such a good hypnotic subject, there was no need to begin with an induction. I knew that whatever induction suggestions I would give would be following her process of going into a trance state, not leading it. So, instead Section A of the hypnosis gets right into presenting pain-control suggestions: the idea that our bodies have a natural healing process, that we don't have to try make ourselves heal because our bodies do it for us in ways that are ineffable, and that we will be reprogramming her nervous system.

Section B is a hypnotic induction, a truncated version of the recording made at the previous session. It includes a deepening procedure predicated on the idea that since we go into trance states all the time, we know the pathway that leads from a normal waking state to a trance state; and we know the pathway so well that we travel down it easily, effortlessly, automatically. That pathway is likened to the path leading from the outside of a hedge maze to the center of the maze - which is a "deep and pleasant hypnotic state.” 
The hypnotic suggestion begins in earnest in Section C, which is a restatement of the formulation we had agreed upon for her pain, complemented by emphatic statements of her overall physical wellness.

Section D has several components, all designed to encourage her to actually direct her attention away from the pain: the pain is simply a nuisance; she has so many more pleasant, more important things to pay attention to; she can be as oblivious to her abdomen as she is to all the other parts of her body in the course of her day; and at various times she will notice that indeed she has been oblivious to her abdomen.

Section E introduces the metronome metaphor. Notice that because of the loosened associations of the trance state, so called "trance logic," it is possible for the therapist to present the pain as a loud alarm, as a rapidly ticking metronome, and as a little 3-D "homunculus" all at once and be confident the client can integrate these three different metaphoric characterizations of the pain into a single gestalt. All through this section, suggestions for pain diminution are interspersed with emphatic suggestions that it all happens gradually and without Amy having to do anything to make it happen.

Amy brought herself out of the hypnotic state before I had a chance to do the usual count from 1 to 5 (“at 3, you'll open your eyes, at 5 you'll be alert, awake, refreshed, feeling good”). She correctly anticipated, from the tone or content of what I was saying that I was about to end the hypnosis. When I inquired what she remembered she reported that she'd been floating in and out of listening. She remembered some, but not most of what had been delivered to her; and she grossly underestimated the amount of time it had taken-a good sign.

Once we were done processing the hypnotic experience, it was time to present the metaphoric task which I was hoping would potentiate the effects of the hypnosis and also give her a sense of doing something active to help herself. I explained that while listening to the hypnosis a number of times was one way of reprogramming her nervous system, I wanted to give her a task-something for her to learn — that would also reprogram her nervous system. I then demonstrated this hand/foot tapping pattern:

\section{L R R L L R R (Hands)}

L R L L R L R R (Feet)

Each column represents simultaneous taps. The foot pattern is the paradiddle, demonstrated earlier with the metronome. The hand pattern is a double stroke roll. One's first instinct is to learn the foot pattern first and then try to place the hand pattern on top of it, or vice versa-but that doesn't work. I explained to Amy that the way to learn the pattern was to learn it all at once, by reading it off the page, column by column, no matter how slowly she had to do it at first. Somehow her nervous system would reprogram itself, eventually, to convert the eight separate columns into the two horizontal patterns that she would then be playing simultaneously. Amy appeared to accept the idea that learning the pattern would be reprogramming her nervous system, but warned me that she didn't have a great sense of rhythm and would have a hard time learning it. I reassured her saying that it was indeed challenging, but that there was no rush 
about learning it and all she had to do was spend a little time practicing it each day. The practice would be reprogramming her nervous system. She agreed to start working on it.

\section{$\underline{\text { Session } 4}$}

Amy opened the fourth session, which occurred 12 days later, saying, "It's actually getting a little better.” I was stunned; I hadn’t been expecting anything remarkably different so soon. Amy went on to report that the pain was "not as consistent." It still could get to 300, but now could go down to 215. She said the pain was not as sharp as it had been; more like a pinch, now, than like a knife. And on a walk with a friend along the Lakefront there had been at least a moment when she was oblivious to the pain. It was hard to know what to make of these subjective impressions. But then Amy listed two objective, observable changes due to decreased pain: First, on that walk with her friend, she was able to go for an hour and a half without having to stop and rest. Before, her limit was a half-hour. Second, she was able to sleep on her right side again. Amy also reported that she was listening to the first recording, the hypnotic induction, at bedtime and that it seemed to be helping her sleep through the night. She'd had middle insomnia on only one night since the last session. On the other hand, Amy had not done well with the tapping pattern. I had her practice it in front of me and it was clear that she was trying to read it off the page much too fast. I had her practice it for a few minutes at a very slow tempo, allowing several seconds for her to set up the proper hand and foot for each column.

Encouraged by all the good news, I decided to push harder with hypnosis, with suggestions for obliviousness, as in the previous session, and with the metronome getting down all the way to zero. I also included suggestions specifically associating the tapping pattern with pain control: "As you consciously try to reprogram your brain by learning this drum pattern...as you find those letters forming a pattern...you feel it in your body as you do it with your hands and feet... and as that becomes more ingrained in your nervous system, this other reprogramming goes forward more powerfully and thoroughly, so that the numbers are getting smaller and smaller and smaller." This hypnosis recording was 22-minutes long. I asked Amy to find the time to listen to it every day in the late afternoon or early evening, and to continue to listen to the recording made at the previous session in the morning.

\section{$\underline{\text { Session } 5}$}

There was no sign of further improvement at the fifth session, 16 days later. There had been no moment during that time when she was aware of a total absence of pain. However her self-rated pain score at the time of the session was 185-the lowest yet for an in-session score. She'd listened to all three hypnosis recordings every day. She had also practiced the tapping pattern but had not mastered it. She'd worked long hours over the past two weeks, and a friend of hers, just a few years older than she, had died suddenly of a seizure. I do not remember her being overly emotional about this loss during the session. I spent the last half-hour hypnotizing her, without recording it, using imagery suggestive of quiet, sheltered, calmness; an invisible dome that encased her wherever she went and whatever she did and protected her from all harm. I don't recall, and my notes give no indication, why I did this. 
S.R. Hamburg

Pragmatic Case Studies in Psychotherapy, http://pcsp.libraries.rutgers.edu

Volume 13, Module 4, Article 1, pp. 284-328, 02-24-18 [copyright by author]

\section{$\underline{\text { Session } 6}$}

At the beginning of the sixth session, nine days later, Amy reported that she was "Good, pretty good" with respect to her pain. She'd had one bad day, when the pain was 280, but the rest of the days were much better. Currently she estimated her pain level at 135 . When writing the notes for the previous session I'd decided to hypnotize her and use imagery I'd used before for people with traumatic memories: you take the memory off your hard drive (your brain/mind) and put it on a thumb drive, put the thumb drive in a shoebox, get on a train that goes to a selfstorage place that is "far away from where you are" and lock it in a locker, and then take the train all the way back to where you are, safe in the knowledge that although it's far away you know where it is and you can get it back if you ever need it. This is what I did, modifying the imagery to accommodate the pain. I incorporated the rhythm of the tapping pattern into the clatter of the train. I asked Amy to alternate this recording with the one from the previous session for the afternoon hypnosis.

\section{$\underline{\text { Session } 7}$}

For whatever reasons, I did not meet with Amy again until 5 weeks later. Her pain had diminished overall during those weeks. She'd had one bad day, when the pain was 280, but on most of the rest of the days it was much less severe, in the range of 120-150. At the time of our meeting it was the lowest it had ever been-76, she estimated. As usual, Amy could not account for the variability in her pain. One day she'd gone for a 3.5-hr walk with a friend and had no awareness of the pain during that entire time. She was still having nightmares, and I suggested doing an $\mathrm{ABAB}$ experiment with the hypnosis/relaxation recording as one condition and an audio book as the other.

The most important event of the past month was that she'd been offered a very desirable job in New York City. A partner from her firm who had moved to a prestigious firm there wanted Amy to join her. Amy felt that she had to give the offer serious consideration, even though she had many reasons for staying in Chicago. But she felt that now that her pain was under better control she actually could think about moving and being away from her family and other local supports. Most of this session, and the ones that followed were devoted to this major life decision rather than to the pain.

\section{Session 8}

At the next session, two weeks later, Amy reported that the pain was definitely subsiding. There had been two days when she had no awareness of the pain for the entire day. She rated these as zero. This was the first time since the onset of the pain that she had experienced painfree days. Amy thought there might be an association between her pain on a given day and the number of steps she took on the previous day (which she was tracking with an app on her phone). I took down the data and after the session did parametric and non-parametric correlations on it, which both yielded strong negative correlations between the number of steps and the pain level. Amy reported that she had been talking to a variety of people about moving to New York, and that they had all been very encouraging about it. It seemed to me that Amy 
herself was now leaning more in favor of it. I explained the importance of feelings in decision making and asked Amy to start reading Focusing (Gendlin, 1982).

\section{$\underline{\text { Session } 9}$}

Amy was about the same at the next session as she'd been at the previous one, 16 days earlier. She'd had two consecutive days of bad pain. These did seem to be associated with an illness she had which also caused a low fever. In this session, for the first time, Amy reported on her tramadol use. (I count my not inquiring about it up until then as one of the two major mistakes in my treatment of her.) She had taken tramadol on only 5 of the 14 days she'd kept records, and on those days she'd taken only one tablet. This radical decrease in her use of the drug was the most convincing evidence to date that the treatment was working.

There were no pain-free days in this interval, but there were a number of days, Amy said, when she had no awareness of the pain for hours at a time. By the numbers, her worst day was 260 , her best were $90-100$, and average days were about 170 . This time, there was no correlation between number of steps she walked and her pain the following day. She was practicing the tapping pattern only intermittently. She could do it reasonably well reading it off the page, but she didn't have it by heart. Sleep was still a problem with both early and middle insomnia. I attributed the sleep problem mostly to stress over the decision about moving to New York. She reported that while her parents were excited about the opportunity there, she wasn't; she just found it "exhausting." She complained that she felt "in over my head...drowning...claustrophobic...everything closing in.” It wasn't the job itself that was making her anxious, but rather the entire upheaval of moving.

\section{$\underline{\text { Session } 10}$}

After Session 9, thinking about Amy's distress over the move it occurred to me that part of her upset was due to thinking of the move as some final irreversible act-when it actually wasn't that at all. I wrote her an email to that effect. At Session 10, which occurred only 5 days after the one before it, Amy said the email had been reassuring and helpful. The only thing about the pain, in my notes for that session, was that on that particular day it was pretty bad and that Amy thought it was connected to her period coming a couple of days early. The only notation about the tapping pattern was that I'd asked her to schedule specific times to practice it for 10 minutes at a time. Clearly, by that point the therapy had come to be mostly about the decision to move.

\section{$\underline{\text { Session } 11}$}

At our session a week later, Amy reported that she was "good...much better." She had talked with her current boss who assured her that if she wanted to come back to Chicago, he'd be happy to rehire her. She was planning to visit New York the next week to scout out places she might live. We spent about 10 minutes at the end of the session practicing the pattern with the metronome, advancing $1 \mathrm{bpm}$ at a time. She was able to play it smoothly (reading it; still hadn't memorized it) at $75 \mathrm{bpm}$. I asked her to practice in this way at home. 


\section{$\underline{\text { Session } 12}$}

When we met again, eight days later, Amy hadn't made the trip to New York; it had been postponed two weeks. Although Amy had just talked with her psychiatrist who also thought that New York was a good idea, her current attitude was, "I want to stay in Chicago.” Her pain was very tolerable overall, with two pain-free days, including New Year's Eve day. But she stayed up late that night and had bad pain on New Year's day, taking $75 \mathrm{mg}$ tramadol four times over the course of that day to try to control it. She rated her pain on that day as 290. Her pain ratings for the other five pain days were, 130, 130, 100, 75, and 220. She'd taken one $50 \mathrm{mg}$ tramadol tablet on two of those days. Her sleep was improved, with uninterrupted sleep most nights. However, the complained that the most recent hypnosis recording - the one with the traincaused her to have nightmares of a monster coming at her from behind. I told her to discontinue that recording and instead go back to listening to the second pain hypnosis recording every afternoon. She was continuing with the first pain hypnosis recording every morning, and the hypnotic relaxation almost every night at bedtime.

Amy was now using her metronome app to practice the tapping pattern (still reading, not from memory) and had gotten up to $97 \mathrm{bpm}$. Then she said something that alerted me to the second big mistake in my treatment of her: that she always found herself "getting hung up on the $10^{\text {th }}$ beat.” But the pattern is only eight beats long. Then I realized my mistake: I'd written out two iterations of the pattern-16 beats. Why? I don't know. All I know is that for the past 47 years, whenever I've written it out for anybody, I've written two iterations; perhaps to make it seem harder for them, certainly making it harder for Amy. When I realized my mistake, I apologized to Amy for it and emphasized that if she could do eight beats she was doing the entire pattern.

\section{$\underline{\text { Session } 13}$}

When we met again, eight days after that, Amy reported that she'd spent the entire time being very nervous about New York, constantly asking herself, “Am I going to fuck it up? Is this the right step?" That very morning she'd woken up so anxious that she had an episode of nausea, coupled with diarrhea. And right after Amy reported this to me she had to rush to the bathroom for another bout of diarrhea. While she was out I decided on an emergency anxiolytic intervention-a travelogue.

I'd first used travelogues a few years before Amy, with a client who couldn't be hypnotized. She was a 60 year-old schizoid, never married, socially isolated librarian who had developed irritable bowel syndrome (IBS) two years earlier. She was cadaverous when we met, having lost 30 pounds due to her illness. Hypnosis has proven successful in the treatment of IBS (Whorwell, 2005). However, when I tried the initial relaxation induction with this woman, instead of becoming relaxed she became more and more tense, physically and psychologically. So hypnosis - in any conventional format, at any rate - was out. Prior to her illness, this woman had enjoyed travelling - motor coach trips through Spain and the south of France, river cruises down the Rhine and the Danube, etc. I'd been to some of the places she had, and somehow it occurred to me to record travelogues for her. I simply had her sit back, close her eyes, and started describing, for instance, walking around Vienna's Ringstrasse: starting at the Schottentor, 
S.R. Hamburg

Pragmatic Case Studies in Psychotherapy, http://pcsp.libraries.rutgers.edu

Volume 13, Module 4, Article 1, pp. 284-328, 02-24-18 [copyright by author]

where the University of Vienna is, then passing by the Rathouse, Parliament, Kunsthistorisches Museum, Hofburg, and ending up at the Café Mozart behind the Opera. The client enjoyed the travelogues and gained back the weight she'd lost. I subsequently used travelogues to good effect with another middle aged woman, who suffered from an idiopathic psychosomatic syndrome.

The travelogue for Amy was a walk up Broadway from Bowling Green all the way up to Washington Heights, then cutting west to Fort Tryon Park and the Cloisters, New York's museum of medieval art. Broadway, for much of its length an ancient Native American path, follows an eccentric, northwesterly course diagonal to Manhattan's prevailing north-south grid. As it successively intersects with the major north-south thoroughfares, it creates some of the city’s world-famous squares-Union, Madison, Herald, Times, Lincoln-and a circle, Columbus. I was hoping that a pleasant, interesting, and deeply relaxed tour along this route would help condition a more positive expectation of New York. Amy did find the travelogue interesting, pleasant and relaxing. I suggested she try listening to the recording whenever she felt the need to calm down.

\section{$\underline{\text { Session } 14}$}

Amy listened to the travelogue on three of the six days between the day it was recorded and our next session. It seemed to be having a positive effect. Amy was now saying that the prospect of New York was still scary but also exciting. Her pain seemed under pretty good control. There were two pain-free days. On another day the pain was bad enough for her to take two $50 \mathrm{mg}$ tramadol tablets. On two other days she took one tramadol. Amy was now busy packing and making other preparations for the move. She attributed the increased frequency of nightmares over the past week to the stress of all this. She'd practiced the tapping pattern hardly at all, so at the end of the session I had her do some practice (still reading) with the metronome set at $100 \mathrm{bpm}$.

\section{$\underline{\text { Session } 15}$}

When we met again, in another six days, Amy reported that her pain had gotten worse, averaging between 150 and 210. And she had taken 10 tramadols over the six days-one on some days, two on others. There was no pain-free day. I immediately asked her if she was listening to the hypnosis recordings daily and, sure enough, she hadn't been. I emphasized to her the importance of daily self-hypnosis in pain control (Chaves, 1993; Hamburg, 2006).

\section{$\underline{\text { Session } 16}$}

By the time we met again, a week later, Amy had been to New York where she had arranged for a sublet. She had also been to Memphis with her boyfriend, visiting his family. Most of the session was spent discussing the boyfriend. Her pain had not been too bad, averaging 80-100 on her subjective scale. There were no pain-free days, but every day there were significant stretches of time that were pain-free. Amy had taken no tramadol at all during the week. She was able to do the first half of the tapping pattern (4 beats) from memory. 
This session marked the end of Amy's formal treatment because she moved to New York the following week.

\section{$\underline{\text { Follow-Up Sessions }}$}

Over the next three months we had five brief follow-up contacts via Skype, the first two at biweekly intervals, the other three monthly. A sixth follow-up meeting, this time in person, then occurred, and then a final in-person follow-up three months after that.

At the first follow-up she was doing well overall, although her sleep continued to be disturbed every night. Her pain was continuing to improve. Two of the fourteen days were painfree, and on most of the rest of the days there were long periods when she was unaware of pain. There was only one bad day, which she rated 170 . She took $75 \mathrm{mg}$ of tramadol that day, her only use of the drug in that period. She was listening to the recordings daily. She could play the two, four-beat halves of the pattern separately and slowly by heart. She could not do all eight beats together. Amy also told this story: Just before leaving Chicago, she had gone to her gynecologist for her annual pelvic exam. The doctor remarked on how calmly and easily she tolerated the exam, in contrast to the year before when she had writhed and screamed in agony.

At the second follow-up, two weeks later, Amy was not quite as well. She was working very long hours on a rush project—from 8:00 am to midnight, some days. She complained of being homesick and missing her parents. And the pain was worse, rated 120-180, with one bad day the previous week. But as before, every day included extended periods with no awareness of the pain. There is no information in my notes on tramadol use, but I imagine she did take some during this period. She was listening to the recordings daily. She had not practiced the tapping pattern at all and in fact had regressed a bit—no longer able to play the second half by heart.

At the third follow-up, a month later, Amy was significantly improved. She had moved to a new sublet that she liked much better than the first. There had been a big improvement in the pain. Amy estimated that $75 \%$ of her days had been pain free. There was a pain "spike" day once a week, rated at 280 . On the other days, i.e. 3 of the 30 , the pain was present but "dull," rated at 150-180. Even on pain days, including the spike days, there were periods of no pain awareness. She'd been listening to the recordings daily but practicing the tapping pattern hardly at all.

At the fourth follow-up, a little more than a month later, Amy reported, "I'm good." Her pain seemed to be about the same as the month before: two or three bad pain days; $60 \%$ of the days, some awareness of the pain but not bothered by it, with pain free periods every day; the rest of the days, about 30\%, pain-free. She had taken two tramadols on one bad pain day and one tramadol on two other days. She was still working long hours and had not practiced the pattern at all.

The fifth follow-up was 26 days later. Six of those had been bad pain days; 8 had been relatively easy pain days; the other 12 , almost half the period, had been pain-free. Amy had taken no tramadol at all. She was listening to the recordings daily but not practicing the pattern. 
She was still working long hours, weekends were hectic, and she was still having trouble with her sleep.

For the sixth follow-up, five weeks after that, Amy was visiting Chicago and we met in person for an hour. She'd had some pain earlier that morning but expected that it would be a tolerable day. There had been two days in the preceding month (i.e. June, 2017) on which she had pain all day. She'd taken two tramadols on each of those days. On three other days, the pain "came in waves" but mostly didn't bother her. On the other 25 days of June there was no pain at all. Amy was listening to three hypnosis tapes daily - the original metronome recording in the morning, and the hypnotic relaxation recording at bedtime. But for the afternoon recording, she had substituted the travelogue for the second pain recording. I was curious as to why but, not wanting to rock the boat, I didn't ask.

At this meeting, Amy was able to do the entire eight-beat pattern, very slowly from memory. By this point I was doubtful about how much the metaphoric task had contributed to her improvement, but I didn't want to take any chances. I wanted Amy to continue working on reprogramming her nervous system, or at least being mindful of having to do it, long after our time together. I directed her to continue practicing until she could play the pattern error free, and without anxiety, at $120 \mathrm{bpm}$. Then she would begin learning what I described as, and indeed is, a much more difficult pattern: a 24-beat sequence juxtaposing the 8-beat paradiddle in the hands with the 12-beat ratamacue-L L R L R L R R L R L R-in the feet. I wrote out the pattern for her and gave her some tips on how to learn it.

Amy was scheduled to return to Chicago, three months after this meeting. We agreed to meet again at that time.

\section{Last Meeting}

We met for the last time exactly three months later, when Amy again visited Chicago. The trend of improvement had continued over the three months. She reported no pain at all during the remainder of July. In the middle of August there was a plumbing catastrophe in Amy's apartment which necessitated her moving in with friends. She had pain on a few days around that time, which she associated with having to carry heavy boxes and suitcases. Otherwise, August was pain free. September was pain free, except for a couple of days at the end of the month. Amy took no tramadol over the three months.

Amy commented that on a few occasions she felt that the pain had migrated from the right side of her abdomen toward the midline of her torso. She didn't seem particularly bothered by that, but it puzzled her. I told her I had no explanation for it, but observed that our nervous system can transmit pain to us from anywhere, in the absence of an identifiable cause, including parts of our body we no longer possess, as in phantom limb pain.

Amy had continued to listen to the metronome hypnosis every morning and the hypnotic relaxation every night. (She reported her sleep to be acceptable but still disturbed.) Now, though, for the afternoons she was alternating the travelogue with the second pain hypnosis recording. She had hardly practiced the tapping pattern at all. Although flustered to do it in 
front of me she did succeed, after a couple of false starts, in executing the pattern once. After a couple of false starts of my own, I managed to execute the more difficult, 24-beat pattern. I reiterated my opinion that it was important for Amy to master the initial pattern and then start practicing the second one in order to maintain the process of reprogramming her nervous system, which she was doing unconsciously via the hypnosis.

At the end of the session I said, "Well, you've graduated." In view of her continued improvement in the absence of contact with me, she was clearly able to continue on her own. Amy felt secure enough in her improvement to agree with my proposal that we schedule no further contacts; she could, of course, contact me whenever she felt like it. I did ask her to send me a Christmas card, when she thought of it, to tell me how she was. I doubt if Amy will need me again. I think her pain will remain under control, and Rachel will be her first choice for anything else. But you never know.

\section{7b. Therapy Monitoring and Use of Feedback Information}

As with Margie's case, no formal monitoring of the therapy was conducted other than the processes described in the above section.

\section{8b. Concluding Evaluation of the Process and Outcome of Amy's Therapy}

\section{Amy's Outcome}

If the improvement lasts, Amy's case will have been one of the most satisfying in my life as a psychologist. (And I confess, I indulge in a measure of possibly premature satisfaction right now.) Amy's problem was distressing and, at least with respect to her career, life-limiting. Others had not succeeded in solving it. Amy's and my work together managed to solve it partially: substantial pain reduction, with an improving trend that augurs further improvement.

Nevertheless, I am left with misgivings. I do not "know" - that is, have a reasonably complete theory or even story about-how the hypnosis worked. I never do. And as a consequence, after more than 30 years, I am still surprised when it works - and doubtful, although it works often enough for me to keep using it in spite of my doubts.

I don't know whether the metaphoric task of tapping to "reprogram” Amy's nervous system potentiated the hypnosis at all. I do believe the hypnosis was the key intervention; there is ample support for that belief (Hilgard \& Hilgard, 1994). On the other hand, the vagaries of Amy's treatment are such that it is just believable that had I simply instructed her to practice the tapping task, to "reprogram” her nervous system, her pain might have subsided. Farfetched as this may sound, it cannot be ruled out.

That there was improvement, however obscure the cause, can be asserted with confidence. We were fortunate to have, from the outset, relatively objective behavioral indices: Amy’s ability to walk farther and longer without resting, and to sleep on her right side. 
Although Amy's subjective numerical ratings of her pain are difficult to interpret, her reports of progressively higher percentages of pain-free days are not. And, of course, there was the radical decrease in tramadol use. I regret that I did not direct Amy to track that carefully from the start. Perhaps I might have if I had been more optimistic, early on, about the outcome, and the possibility of writing up her case.

\section{A Common Element in Amy’s Case and Margie’s Case}

Different as they were from each other, the cases of Margie and Amy were alike in that a metaphoric task figured prominently in both. They were alike in another metaphoric aspect: where the therapist is seated with respect to the client. It has been evident, since the beginning, that where the therapist and client are physically placed in the consulting room is symbolically freighted (for example, the analyst's couch).

When the therapist and client sit opposite each other, far enough away so their feet won't collide, they are enacting a relatively formal, businesslike relationship with each other. There is little solidarity in that positioning. When you are sitting next to somebody it is altogether different. You are literally on the same side, and it can easily come to feel that way. Sitting next to each other is the way people often do things together, especially when focusing on a common objective. Teachers of piano, drawing and painting, and reading sit next to their pupils, the better to help them learn. And, of course, when we want to comfort someone, the natural impulse is to sit next to them.

So when I sat on the floor with Margie doing the puzzle, and next to Amy in front of the computer screen, experimenting with the metronome, we were for a brief moment not just physically but emotionally closer than before. We had permeated the role boundary of therapistclient in which the one does something to the other, and emerged as just two people doing something with each other, discovering something together. I feel the difference and I think the clients do, too. We both know that we are symbolizing fellow feeling and commitment.

\section{REFERENCES}

Alexander, F. (1948). Fundamentals of psychoanalysis. New York, NY: Norton.

Azrin, N.H. (1977). A strategy for applied research: Learning based but outcome oriented. American Psychologist, 30, 469-485.

Chaves, J. F. (1993). Hypnosis in pain management. In J. W. Rhue, S. J. Lynn, \& I. Kirsch (Eds.), Handbook of clinical hypnosis, 511-532. Washington: American Psychological Association.

Damasio, A. R. (1994). Descartes' error: Emotion, reason, and the human brain. New York, NY: G. P. Putnam.

Eysenck, H. J. (1965). Fact and fiction in psychology. Baltimore, MD: Penguin Books.

Fishman, D. B. (2013). The Pragmatic Case Study Method for creating rigorous and systematic, practitioner-friendly research. Pragmatic Case Studies in Psychotherapy, 9(4), Article 2, 403-425. Available: http://pcsp.libraries.rutgers.edu

doi: http://dx.doi.org/10.14713/pcsp.v9i4.1833 
Pragmatic Case Studies in Psychotherapy, http://pcsp.libraries.rutgers.edu

Volume 13, Module 4, Article 1, pp. 284-328, 02-24-18 [copyright by author]

Frank, J. D. (1973). Persuasion and healing, $2^{\text {nd }}$ ed. Baltimore, MD: Johns Hopkins University Press.

Gawande, A. (2004, December 6). The better doctor. The New Yorker. http://www.newyorker.com/magazine/2004/12/06/the-better-doctor

Gendlin, E. T. (1962). Experiencing and the creation of meaning: A philosophical and psychological approach to the subjective. New York, NY: The Free Press.

Gendlin, E. T. (1982). Focusing. New York, NY: Bantam New Age Books.

Goodman, N. (1972) Seven strictures on similarity. In N. Goodman (Ed.)., Problems and projects, 437-446. Indianapolis, IN: The Bobbs Merrill Company, Inc.

Greenberg, L. E. (2002). Emotion-focused therapy: Coaching clients to work through their feelings. Washington, DC: American Psychological Association.

Hamburg, S. R. (1983). Reading aloud as an initial assignment in marital therapy. Journal of Marital and Family Therapy, 9, 81-87.

Hamburg, S. R. (1985a). Leaving the consulting room to provoke enactment in marital therapy. Journal of Marital and Family Therapy, 11, 187-191.

Hamburg, S. R. (1985b). When not to recommend separation counseling. Psychotherapy, 22, 740-742.

Hamburg, S. R. (1998). Inherited hypohedonia leads to learned helplessness: A conjecture updated. Review of General Psychology, 2, 384-403.

Hamburg, S. R. (2000). Will our love last? A couple's roadmap. New York, NY: Scribner.

Hamburg, S. R. (2006). Hypnosis in the desensitization of fears of dying. Pragmatic Case Studies in Psychotherapy, 2(2), Article 1, 1-30. Available: http://pcsp.libraries.rutgers.edu/ doi: http://dx.doi.org/10.14713/pcsp.v2i2.873

Hamburg, S. R. (2010). Getting over a rough spot. In A. S. Gurman (Ed.), Clinical casebook of couple therapy (pp. 308-330). New York, NY: Guilford Press.

Hamburg, S. R. (2012). The newlyweds book: Ten helpful hints for your happy marriage. [Amazon Kindle Version]. Retrieved from https://www.amazon.com/Newlyweds-Book-Helpful-HintsMarriage-book/dp/B00897H09A/ref=sr_1_1?ie=UTF8\&qid=1503765810\&sr=81\&keywords=hamburg, +newly+weds Herrigel, E. (1953). Zen in the art of archery. New York, NY: Pantheon.

Hilgard, E. R. \& Hilgard, J. R. (1994). Hypnosis in the relief of pain. New York, NY: Brunner/Mazel.

Jacobson, N. S. \& Christensen, A. (1996). Integrative couple therapy: Promoting acceptance and change. New York, NY: Norton.

Johnson, S. (2011). Hold me tight: Your guide to the most successful approach to building loving relationships. London, UK: Piatkus Books.

Lakoff G. \& Johnson, M. (1980) Metaphors we live by. Chicago, IL: The University of Chicago Press.

Lazarus, A. A. (1971). Behavior therapy and beyond. New York, NY: McGraw-Hill.

Lazarus, A. A. (1981). The practice of multimodal therapy. New York, NY: McGraw- Hill.

Levitt, H.M., \& Piazza-Bonin, E. (2016). Wisdom and psychotherapy: Studying expert therapists' clinical wisdom to explicate common processes. Psychotherapy Research, 26, 31-47. http://dx.doi.org/10.1080/10503307.2014.937470

Mahoney, M. J. (1991). Human change processes: The scientific foundations of Psychotherapy. New York, NY: Basic Books. 
S.R. Hamburg

Pragmatic Case Studies in Psychotherapy, http://pcsp.libraries.rutgers.edu

Volume 13, Module 4, Article 1, pp. 284-328, 02-24-18 [copyright by author]

McLeod, J. (2015). Narrative case studies and practice-based learning: Reflections on the case of "Mr. R." Pragmatic Case Studies in Psychotherapy, 11(4), Article 2, 239-254. Available: http://pcsp.libraries.rutgers.edu/ doi: http://dx.doi.org/10.14713/pcsp.v11i4.1928

McMullen, L. M. (2008). Putting it in context. In R. W. Gibbs, Jr. (Ed.), The Cambridge handbook of metaphor and thought, 397-411. Cambridge, UK: Cambridge University Press.

Patterson, D. J. (2010). Clinical hypnosis for pain control. Washington, DC: American Psychological Association.

Seligman, M. E. P. (1990). Learned optimism. New York, NY: Random House.

Sullivan, H. S. (1954). The psychiatric interview. New York, NY: Norton.

Whorwell, P. J. (2005). The history of hypnotherapy and its role in the irritable bowel syndrome. Alimentary Pharmacology \& Therapeutics, 22, 1061-1067.

Wolpe, J. \& Lazarus, A. A. (1966). Behavior therapy techniques: A guide to the treatment of neuroses. New York, NY: Pergamon.

\section{Table 1. My Approach to Hypnotic Suggestion (from Hamburg, 2006, pp. 6-7)}

Like most hypnotherapists, when I craft a hypnotic suggestion I attempt to combine images of the desired behavioral change with direct suggestions for behavioral change, as in the driving example cited above. All my hypnotic suggestions begin with a generalized suggestion for rapid change:

Sometimes the psychological changes we experience in our lives happen slowly and gradually. For example, as we grow older we gradually become more mature and wiser...or as we get to know someone over time we realize that we like them more and more. But some psychological changes, sometimes big ones, can happen very quickly, almost instantly. Some of these very rapid psychological changes are unpleasant, like [in the case of a post- traumatic phobia] what you experienced some time ago. But some of these very rapid and very big changes are pleasant ones...they are changes we very much want. Falling in love is one of those pleasant changes that many people experience almost instantaneously. That's why we have the phrase, “love at first sight.” Religious conversion is another huge psychological change that can happen to people in an instant. Something touches you and suddenly the whole world looks different....And the interesting thing is that we don't really do anything to make these big and pleasant changes happen to us....they just happen...and it's hard to say why...So if in these next weeks or even days or even hours you find yourself feeling much better than you have, you might wonder why...but it doesn't really matter...Was it this hypnosis, this tape? Maybe, maybe not...it really doesn't matter...all that really matters is that you feel better...and it really doesn't matter why because big positive changes like this happen all the time...they just happen.

Usually, I do not prepare the rest of the hypnotic suggestion in detail in advance. I have a general idea of what I am going to do; and I have notes, usually that the patient has written him/herself, outlining the major images and statements I will use. From there, I improvise. 


\section{Table 2. Script of Hypnotic Induction Employed In Session 3 of the Therapy With Amy}

Note: this script is divided into five sections: A, B, C, D, and E.

\section{Section A}

OK...OK Amy...I'd like you to get comfortable where you are...get real comfortable, do whatever you want to get real comfortable....and once again I'm going to just do the little minimal stuff that I have to do to help you get from a normal waking state to a deep and pleasant hypnotic state...And we're doing this because there really is a way that our unconscious mind can help us do things in ways that we can't verbalize... Our bodies know how to do these things without our being able to say...

So just as you can learn how to play a musical passage quickly, or a pattern quickly, you can't say how you did it, your body did it for you... And it's a wonderful thing about our

bodies...they just have this knowledge of their own. Of course, our bodies have a natural healing process which is quite amazing when you think of it...that if you cut yourself somehow your body knows how to reconstitute itself just to be back where it originally was... and how it knows that of course we can't say but it does it automatically and we don't have to think about it.

We just know that's gonna happen. And so in this recording and over the next weeks, we're going to utilize, tap, the power of your imagination, and of your unconscious mind, and of your body to reprogram your nervous system in ways we can't say how you're gonna do it-I don't know how you're gonna do it—but you can find a way to do it. And you don't really even have to think about it. It just...happens.

\section{$\underline{\text { Section B }}$}

And as you walk through this maze that will get you to the deep and pleasant hypnotic state, of course you don't have to think about where to turn right or where to turn left because even before you listened to the original recording you knew your way down that pathway. And now that you have...listened...to the original recording you know that pathway even better. So you just automatically turn left when you need to turn left, and right when you need to turn right...

And each turn you make gets you deeper and deeper into the maze, closer and closer to the very center of the maze, which is a very deep and pleasant hypnotic state. And as you get deeper into the maze you begin to notice the various things that do happen. When you get deeper into it you start to notice that the various sounds you can hear-sounds from inside wherever it is you're at, from your apartment—sounds from outside...buses going by on the street on Pacific Avenue-your experience of comfort and well being...every sound, every feeling, every sensation, all of that can just become more and more a part of that experience of comfort and well being... as you turn right and as you turn left easily, effortlessly, automatically, realize that all these sounds just become incorporated into this experience of comfort and well 
being... using this ability that all of us have-and creative, artistic people have more of it — to get deeper and deeper into the maze, closer and closer to the very center of the maze.

And it's almost as if with every breath you take you do get deeper and deeper into the maze, closer and closer to the very center of the maze which is a very deep and very pleasant hypnotic state. And as you get...deeper and deeper into the maze, you begin to notice a feeling of warmth, a pleasant feeling of warmth somewhere in your body, and certainly that pleasant feeling of heaviness, just all over...just that feeling you get from letting the entire weight of your physical self be supported by what you're reclining on...just that feeling you feel like after you've taken a long swim and you pull yourself out of the pool and you just feel this wonderful feeling of heaviness in all your muscles... as you get deeper and deeper and closer and closer....

And I don't know where you're in the maze, you know, maybe still en route, or maybe you are sitting on the bench looking at the flowers. So if you wish you can just sit there on the bench, but maybe you would like to lie down on that thick soft green grass just as you're lying on what your lying on right now... and look up at the blue sky...We've had such beautiful clouds in the sky the past few weeks, and I'm sure you've looked at them and marveled at the shapes and at the colors and how the shapes change, how clouds morph as they pass by on the breeze, how they change from one thing into something else in amazing and wonderful ways... and how the clouds change color as the angle of the sun changes and how they become colors that you couldn't possibly imagine, given that we think of clouds as being white or gray, but they can be blue, they can be pink, they can be yellow, they can be orange, bright red even sometimes...all depending on the angle of the sun...atmospheric things... I don't know what the clouds look like that you may be seeing in your mind's eye...I hope they're ones that are interesting and pretty for you to look at... as they float by on the breeze and morph and change colors in new and surprising ways...

\section{Section C}

And as you just continue to lie there and watch the clouds as they pass by and be interested in their shapes and their colors I'm going to talk more with you about what we talked about before when we were sitting by my computer and also about this natural healing power and about the ability of your brain to reprogram itself....And you and I have agreed —and it's most probably the case - that the part of your body that is not working right is not any of your internal organs down in the lower right part of your abdomen, but just your nervous system, your pain signaling system.

And it's kind of comforting to think that all that you're feeling is essentially a false alarm...that's all it is...It's not a signal that anything is wrong because we know that nothing is wrong. You've been checked every which way, and there is nothing wrong, thank goodness. You're healthy and you're young, and you're vigorous, and there's nothing wrong with your organs; but there is something wrong with your pain signaling system....that has caused somehow a false alarm to just kind of perpetuate itself. And just like with the car alarm, two years ago whatever started it going could have been something very small. It could have been as you were digesting something that wasn't something that agreed with you or that you were slightly allergic to... or something... who knows. Maybe it was some mechanical thing as you 
just slightly moved and some nerve got changed in its displacement—but something very tiny caused the alarm to just start.

And unfortunately, unlike the modern car alarms this alarm kept on happening and caused you terrible fright and terrible grief...And it's so reassuring to know that after all these medical tests we know - you know - that you are basically in very good health, that there is nothing wrong aside from the fact that there's been this glitch in your pain signaling system so that this alarm, that should have shut off a long time ago, is still going. But the thing is that you are aware and I am aware that it's not signaling that there's anything terribly wrong, it's not signaling anything to cause fear or even anxiety.

\section{$\underline{\text { Section D }}$}

You're certainly justified in feeling frustrated by it. You're certainly justified in feeling that it's a nuisance - an unnecessary negative thing that you don't really need to deal with, that you'd much rather not pay attention to... because after all you have so many positive things to pay attention to in your life...your creative work, your designing, your sketching...dealing with the exciting people in your work...your friends, your family. There's so many pleasurable things and worthwhile things that you really do want to pay attention to and that you do pay a lot of attention to and you certainly don't want to be distracted by anything that's a nuisance.

And why should you be distracted by anything that's a nuisance? Really...not necessary. It would be perfectly fine-of course you'd love it - if you didn't have to pay attention to these sensations from your lower right abdomen forever. I mean, think about it: As far as you're concerned, almost all the time the lower left side of your abdomen-it's as if it doesn't exist. You're not aware of it, you're not thinking about it.

When you're talking with a client at a building site, when you are constructing a model of a project, when you are making a drawing, you're not thinking about the lower left part of your abdomen, just as you're not thinking about your left knee, or the big toe on your right foot. You go through your life and you do the things you like to do and love to do, and spend time with the people who mean a lot to you and whom you care about and you use your body, and it does what you want it to do, but at the same time you're not aware of your body as such...

I mean, when you walk down the street, you're not aware of your left heel or the arch of your right foot... Or when you're eating dinner you're not particularly aware of how your thumb and forefinger feel as you hold your knife and fork. Your body just does what it does and you don't really pay attention to what your body feels like as you do these things...because you have more important things to pay attention to. Your body-all these different parts of your bodyjust kind of take care of themselves.

And, wouldn't it be nice, if sooner or later, the thought would occur to you, that gee whiz the lower right part of my abdomen is starting to take care of itself too. I don't know when it might be. It could be when you're going to work, or it could be when you're getting ready for bed, or could be just after you've finished texting somebody, that it occurs to you that, gee whiz, while I was texting that person I guess...the lower right part of my abdomen was just taking care 
of itself...because I wasn't that aware of it while I was texting that person... Or maybe it might be after you've searched for some ideas or something on the internet...because you're looking for some specific buildings from some specific time or place. And you finish doing that search and the thought occurs to you that wow, I guess that just like my left heel has taken care of itself while I did this search, just as my right knee took care of itself as I did this search, so did the lower right part of my abdomen just kind of take care of itself while I did this search because I wasn't paying a whole lot of attention to it. It was almost as if it didn't exist-just like while I was doing the search it was almost as if my right knee or my middle finger of my right hand or my eyelashes or my right ear didn’t exist because I wasn't aware of any of the sensations coming from those parts...so it was as if they didn't exist. And maybe for that brief time it was almost as if my right abdomen didn’t exist....

\section{Section E}

Wouldn't it be nice to notice...from time to time...that that's happening...that somehow it's becoming...less loud. It's almost as if it had been set for a long time at 300 but somehow, using the power of your unconscious mind and the power of your imagination you were able to click it down to 299... And you know there's not much of a difference between 300 and 299 but you know that if it's 299 it's less. And if it can go down to 299, then the power of your imagination of your unconscious mind can click it down one more click to 298. And you don't try to make it happen; you kind of just go with it as it happens.

Just like with that drumstick example, just a matter of going with these very slight changes... and if the changes are very slight—smaller than we can even notice-as long as the changes are that small...it's easy.... and effortless for us to go along with them. We don't have to try. It's funny how it can feel different and yet seem almost the same as it becomes different...From moment to moment as the loudness clicks down, we can't hear-you can't hear that difference as it clicks down from 298 from 297. You can't hear that difference. You can't even hear that difference as it clicks down to 296. And then it goes down to 295-again easily, effortlessly. When it goes down that slowly one click at a time you just kind of go with it, and it's easy to go with it... as it goes down so slowly and gradually. You don't have to strain because in a funny way it seems like it's the same but you know it's getting lower. And you're just going with it.

You get down to 294, then 3 then 2 and 1 and then to 290. And then, if you take a moment to think about it, as it was in the process of going down from 300 to 290 you couldn't really tell that it was going down, as it was going down-and as you were easily and effortlessly going with it. But then when you compare 290 to 300 you can really see that the loudness of that pain, that the loudness of that alarm, is noticeably less at 290 than it was at 300 . But as it was happening so gradually and so easily and effortlessly - and as you just went with it, as you followed the clicks as they went down, as the clicks just lead you where you needed to be led, it seemed like nothing was changing. It seemed...easy.

And it's only when you got to 290 and then could compare that to 300 that you could notice that wow this really is...lower, quieter...the alarm has quieted...noticeably. And as the minutes and days and hours go by, at various times that neither you nor I can predict-and we 
don't have to predict—it clicks down a notch...from 290 to 289 and from 289 to 288 and then down to 287. From there to 286. And it's easy, it's effortless. As it's happening you don't really notice when it's changing or how it's changing because these changes from one click to the other are so...tiny. And you just easily go along with these changes: 285. 284, 283...various times and various places that you can't predict and I can't predict but sooner or later you get down to...280.

And then when you compare that to 290 well that's noticeably quieter than 290 -and quite a bit quieter than 300. But as it was happening, you were hardly trying-you weren't trying to make it happen. You were just following those clicks as they clicked themselves down. And it was easy for your body to follow those clicks down. And yet you get to 280 which is really a lot less than 300. And you feel the loudness of that alarm diminishing and shrinking...like that little homunculus is shrinking inside of you, just shrinking. And then you go down to 279 and of course I don't know when these clicks happen. You may not even notice them happening as they happen because they're tiny changes from one click to the other. From 279 to 278 to 277 . These are very small little...clicks.

And it's very hard just to tell the difference between 279 and 278, and 278 and 277 and so on...but by the time you get to $270 \ldots$ and then you notice...the alarm is even softer now than it was at 280. And you can certainly tell the difference between 270 and 290... and you really can tell the difference between 270 and 300. And it's so wonderful to feel that your body's natural healing process in combination with the power of your imagination and your unconscious is able to click this thing down so that very gradually as it's happening you don't even notice that the loudness is clicking down one click at a time.

It's only after it's gone down 10 clicks, 20 clicks, that you can really become aware that this process that's been happening so easily, effortlessly has come a long way... and the loundness is much, much less than it was....and that little homunculus is getting smaller and smaller. Maybe it was the size of a baseball but maybe it's gone down to the size of a Ping Pong ball... and maybe by the time you get down to 200-because you're gonna get down to 200 it just goes just one click at a time so easily and effortlessly. It's so easy to get from 201 to $200 \ldots$...it's nothing, such a short distance. But by the time you get down to 200, the loudness is so much less, it's so much softer and that little homunculus creature there has shrunk to the size of a Ping Pong ball.

And you just continue so easily and effortlessly to go below 200...199, 198, 197... and then down below $150 \ldots 149,148,147,146 \ldots$ and now you really feel the difference: the loudness is so much less, the loudness of that alarm. It's now a kind of loudness that you can dismiss, just as you dismiss the sound of a passing bus or cars going by. You can live your life with cars going by, with buses going by. They just become part of the landscape. And you kind of just...they become the background-and a very dim and faint background... as you continue to go down just one click at a time - there's not rush about this - it takes time just as it takes time to learn something, to play something really really fast. You don't do it all in one day. Your mind, your nervous system needs time to program itself, as I'm going to show you after this hypnosis. 
It takes time, but it happens, it's inevitable because if your unconscious mind keeps on working at it, you don't have to work at it. Your body works at it. You don't work on healing your hand if you've cut it; your body works on it. You don't have try to make it happen; it just happens. Well, likewise with this: there's nothing for you to do, nothing for you to try to do. This is up to your body and your unconscious mind and the powers of your imagination. And you leave it up to your body and your unconscious mind and the powers of your imagination to reprogram your nervous system so that the loudness keeps on going down, click by click by click by click. You get below...100. And I don't know when it's going to be, and we don't have to rush it, we don't have to have any particular expectation. The main thing is that it's all going in the right direction.

The main thing is that it's getting softer and softer and softer, easier and easier to just put out of your mind, so you can pay attention to the things you love and the people you love and to the good things in life, and just let your body take care of you, the natural healing power of your body. Let the power of your unconscious take care of you, the power of your imagination take care of you... as you reprogram this signaling apparatus of your nervous system, and get it back to where it's supposed to be. As you keep going down, click by click, getting closer and closer and closer...to zero. And as you get closer and closer, that little creature there gets smaller and smaller - the size of a marble...the size of a pea...the size of a ball bearing or a BB...the size of a grain of sand, just smaller and smaller... as the loudness gets so soft that it's almost as if it's not there. You may have some sense that it's there, but it doesn't matter...because it's so soft it doesn't matter...

It's become so soft in this gradual process of clicking down one click at a time so that you can't even tell from one click to the other that it's getting softer-but you know it is, it must be-but every 10 or 15 or 20 clicks you can tell it is getting softer. You can tell that big a difference. But as it's happening it's so gradual that you can hardly tell it's happening and you don't have to tell that it's happening while it's happening. You can just enjoy those moments when you realize "My goodness...I'm feeling so much more comfortable.” It must be happening; my body must be taking care of me.

And it might be happening when you're riding on the CTA [train] or riding on a bus or maybe visiting your parents' house. I don't know when it might happen. It might be when you're watching a favorite TV show and you realize "Wow, I'm feeling so much more comfortable now.” Well of course you are because your body is taking care of you and your unconscious mind and the powers of your imagination-as you harness these powers to help you, without your even trying, click down the loudness that it becomes so soft that it doesn't matter, so that that little homunculus that little creature is down to the size of a grain of sand or a crystal of salt, something like that.

Almost small enough that it can just dissolve just like a crystal of sugar can dissolve in a cup of tea. So much more comfortable. But there's not pressure-no pressure on you to do anything. You can just go on with your life and let your body take care of you, let your unconscious mind and the powers of your imagination take care of you. And every once in a while, when it's clicked down 15 or 20 clicks or 30 clicks suddenly become aware of it—maybe 
when you're waiting at a corner, standing at a traffic light to notice that the sound is becoming softer and softer, so soft that it really doesn't matter anymore...

And now Amy I'd like you to take a minute to just enjoy how you're feeling now... and enjoy thinking about how your natural healing process and the power of your unconscious and of your imagination can help you... and look forward to whatever you're going to be doing that's going to be fun over these next couple of weeks. [At this point Amy spontaneously brings herself out of the hypnotic state.] 


\section{APPENDIX 1: THE DEVELOPMENT OF MY MODEL FOR CONDUCTING PSYCHOTHERAPY}

Editor's Note: As one perspective for gaining additional context about the nature of Dr. Hamburg's model for conducting psychotherapy, I asked him to address the question of how his present model developed, after 47 years of training and practice. I view this perspective as related to an area in the psychotherapy literature devoted to the nature and development of psychotherapist "wisdom." For example, writing in this journal, McLeod (2015) points out that

In the future, "professional wisdom" case studies may come to be seen as an important category of evidence within the broad professional knowledge research agenda introduced by Fishman (1999). There have been many studies, including pragmatic case studies, that have analyzed the practical strategies and concepts used by therapists when working with specific groups of clients. Wisdom research takes this a step further. Wisdom is the product of reflecting not just on a specific aspect of professional work, but on the entirety of a lifetime of professional practice. One of the striking characteristics of therapist wisdom studies is that they generate a nuanced, modest and broadly "integrative" understanding of therapy process and outcome that is in many respects at odds with the conclusions of the empirically-validated therapy literature. For example, in interviews conducted with therapists nominated by their peers as possessing wisdom, Levitt, \& Piazza-Bonin (2016) found that willingness to embrace ambiguity and uncertainty emerged as a key theme ( $p$. 251).

\section{Experience as a Client}

My stance as a psychotherapist has been influenced chiefly by my experience as a patient in psychotherapy. Even now, more than 50 years later, I remember the intensity of my psychological suffering and my desperation for effective help. Unfortunately, it was not to be forthcoming. The first therapist was a young, new psychology professor who also did duty in my college's counseling center. He seemed nervous and, over the eight months I spent with him, uttered hardly a word. I concluded that he didn't know what he was doing-an opinion I still hold-and asked the director of the center for a referral to a practitioner in the community. The director referred me to the psychologist who, he said, was his own therapist. I was grateful for this referral to someone in whom I could have confidence.

The second therapist was an experienced man, in his late 40s at the time I met himabout the age I was when I treated Margie. Peter Gill was intelligent and confident, engaged and caring. And contrary to many therapists of that era, and even this, he did not hide behind a mask of therapeutic neutrality: he was emotionally transparent and self-revealing. Occasionally he offered direct advice that I am glad I followed. He was a fine therapist-but the psychoanalytic model within which he practiced seemed to me to be stultifying and to choke off most of the benefits that his natural gifts might otherwise have yielded.

He was clear enough about it at the outset: Change would be slow, requiring the development of a transference and then the analysis of it - through which healing would finally 
S.R. Hamburg

Pragmatic Case Studies in Psychotherapy, http://pcsp.libraries.rutgers.edu

Volume 13, Module 4, Article 1, pp. 284-328, 02-24-18 [copyright by author]

flow. I was not happy about change taking so long but I accepted it because, after all, it was the Truth. Everybody knew it was the Truth.

It is now hard to believe, but easy to remember, that the hegemony of psychoanalysis inside and outside of psychology in the 1950s and early 1960s was such that ideas I now regard as empirically unfounded and in a number of instances intrinsically problematic were generally understood, then, as being self-evidently and inevitably true.

I put all the faith I had in the therapy with Peter Gill, and worked as hard as I could at it. By the end of two years of working at it, I was forced to the grim conclusion that it wasn't doing any good-I just seemed to be waiting for change to happen-and I quit.

Not long after that, in my last semester at college, out of curiosity and the need for a few more credits to graduate, I took my first psychology courses-in abnormal psychology and personality theory. They were taught by Brendan Maher, a rigorously scientific experimental psychopathologist. For me, those courses were disturbing and disorienting: there was no such thing as the subconscious; no id, ego, superego; personality was not formed by early life experiences processed through the oral, anal, and genital stages of development; psychological symptoms were not the coded expression of larger, deeper conflicts but, rather, always just the cigar.

These claims, presented by Maher in a calm, matter of fact, clipped British manner, seemed logical and reasonable. But if they were true, then all that I had previously believed about psychology wasn't. I didn't know what to do with this contradiction. It bothered me, but I was moving away from psychology anyway_about to enter journalism school. So, as I recall, I just tried to put it out of mind.

Not altogether successfully: Only a couple of months after graduation, browsing in a bookstore, I came across Fact and Fiction in Psychology by H. J. Eysenck (Eysenck, 1965). I must have been familiar with the name from Maher's course on personality. In contrast to Maher who was modulated and understated, Eysenck was a polemicist. And it was his polemics that converted me from psychoanalysis to behaviorism. I say "converted” because it was indeed an intense conversion experience, akin to a religious conversion. It was not that I soberly and dispassionately weighed the evidence and by my own agency changed my opinion. Rather, Eysenck provided a balm for my lingering, bitter disappointment with the psychotherapy I had received. His persuasive communication offered up the hope that people's psychological ills could be cured by a psychotherapy based on science; and it provided just enough grounds for the faith that this hope would be fulfilled.

What I mean to emphasize is that my switch from psychoanalysis to behaviorism was not purely rational. I did not, at that time, know enough about either to make a reasoned determination that the one was wrong and the other was right. This decisive shift in my intellectual outlook was powered by and powered - the causation goes both ways - a great wave of emotion. In brief, the switch made me feel wonderful and that is largely why I made it. If felt liberating and cleansing to be a behaviorist. And it gave me a sense of life-direction and purpose: I would devote myself to a new, problem-focused, action-oriented, brief psychotherapy. 
I would demonstrate that this was possible and thus redeem, at least in part, my own unfortunate experience with the old-style treatment. (Forty-seven years later, I can say that I am reasonably satisfied with my degree of success in that mission.) So I told Columbia I wasn't coming and started studying psychology.

\section{Graduate School}

I eventually got into graduate school, where I did not amass much clinical experience. My first confrontation with the challenge of doing effective psychotherapy came only in my internship. I had the good fortune to do it at the Palo Alto VA Hospital. The director of training back then was Donald T. Lim, a shrewd, perspicacious and very kind man whom I remember with great affection. Dr. Lim directed me to the outpatient clinic as my first placement. It was September 1975, just a few months after the end of the Viet Nam war and there was no lack of seriously troubled clients. My supervisor was John Marquis, an ardent behaviorist who gave his supervisees carte blanche. I soon discovered that the behavior therapy techniques in which I'd invested my faith (a) were too limited in scope to comprehend the wide variety of problems my clients presented, and, more seriously, (b) gave no clue as to how to conduct a conversation - which is what psychotherapy fundamentally and inevitably is.

What to do? I wasn't going to revert to psychoanalysis; that was impossible for me. Instead, I fell back on the Rogerian listening techniques-reflection of content and affect, and summary reflections - that, in my graduate program as in most, had been taught as the saline solution of psychotherapy. That is, Rogerian techniques were (I guess, still are) presented as a neutral vehicle to keep the conversation going, within which you would drip the curative stuffbehavioral directives, psychoanalytic interpretations, what have you. When Rogerian techniques were taught to me in graduate school, I had dismissed them as "touchy-feely" and because they were associated with a meandering, "non-directive" psychotherapy that was antithetical to how I wanted to practice. But now, in Palo Alto, they were the only arrows in my quiver, so I used them. And gradually I came to discover that far from being saline, they were, as Rogers claimed, curative.

As this was going on, I belatedly availed myself of something else on the graduate school menu that I had eschewed: I read Sullivan's The Psychiatric Interview (Sullivan, 1954). It was wonderfully illuminating, and forever after I have been guided by two of its major points: (a) that the cause of most mistakes in psychotherapy is the therapist's anxiety (and therefore therapists must always be monitoring themselves for it); and (b) that the therapist's central task is to understand exactly what the client means by what the client says. Sullivan was also impressive in how precise he was about what to do and not to do in psychotherapy. The writers on psychotherapy whom I most admire-Lazarus, Haley, and Leslie Greenberg, among others—all share that quality.

By the end of my internship I was still floundering, but I made the optimistic presumption that effective psychotherapy was out there somewhere. I just had to find it. I had begun assembling a set of experiential propositions to guide my work. 


\section{Early Years After Graduate School}

Reading and clinical work over the next four years enabled me to more fully articulate and elaborate my set of experiential propositions:

1. Feelings are the fundamental and primary mode by which human beings respond to their engagements with the world.

2. Cognitions are always embedded within a matrix of feelings; that is, there is no such thing as a cognition without an emotional valence.

3. The causation between feelings and cognitions can go both ways.

4. Feelings are, in their essence, information for guiding behavior. (This idea, originally advocated by "soft-headed" humanistic psychologists such as Gendlin [1962] was, after a considerable time lag, taken up and confirmed by "hard-headed" neuroscientists, such as Damasio [1994].)

5. A primary task of psychotherapy is to help clients attach a verbal code to that information so that it becomes more available for decision making - in traditional lingo, to help clients "get in touch with their feelings.”

6. The psychotherapist does this, first of all, by closely tracking the client's experiential flow, i.e., how the client felt during the events he or she recounts in the session, and especially how the client is feeling in recounting them.

7. The therapist does this by continually making inferences about the client's feeling state and confirming/disconfirming them via reflections of affect.

8. It is possible, sometimes, for a therapist to change a client's way of thinking and feeling about an event by delivering a carefully crafted summary reflection of affect that emphasizes and makes connections between some aspects of the client's experience of the event, while de-emphasizing others.

None of this, in my view, contradicted being a behavior therapist. After all, the heart of behavioral analysis is the identification of the variables that control behavior. I had simply come to the conclusion that, for human beings, those variables - in Skinnerian terms, the discriminative stimuli-were not objectively specifiable but rather a matter of the organism's subjective interpretation. (And, who knows, that also might hold for the rats I trained in graduate school.)

So I continued, up to the present day, to operate in accordance with these behavioral principles:

1. Psychotherapy is a form of education in which the therapist necessarily provides information, makes suggestions, gives directives, and offers opinions including value judgments. 
2. Therapy is present-oriented, problem-focused, and as brief as is consistent with the achievement of its narrowly defined behavioral objectives. (The operative question, posed in the first session is, "Let's say we met 10 to 15 times, and at the end of it you could say 'It really helped.' What would you be doing then-be able to do then-that you can’t do now?”)

3. The major impediment to learning new behaviors - the major impediment in life generallyis anxiety. Therefore, the major task of psychotherapy is anxiety desensitization. The therapist accomplishes this by engineering imagination-based and/or in-vivo exposure tasks for the client to perform outside the sessions.

4. Sessions are used to persuade clients to go through with the exposure tasks. This is done first by trying to understand their anxiety and then by having them imagine in detail, and discuss, what it might be like to perform the tasks. The most important moments in this sort of therapy, then, are conceived to occur outside the consulting room. (Margie's case was exceptional in that the dramatic, pivotal moment occurred in the consulting room. If I had been more thorough, at the previous session, in preparing her for the puzzle task, that moment might have occurred outside the consulting room for her, too. It wouldn't have made as good a story, but I would have preferred it that way.)

Two psychologists were particularly influential to me early on, and remain so now-Arnold Lazarus and Nathan Azrin. I became acquainted with Lazarus's work in one of the first books I read after my "conversion,” Behavior Therapy Techniques (Wolpe \& Lazarus, 1966). And I remember the sense of fresh air that I felt when I read Behavior Therapy and Beyond (Lazarus, 1971). The idea of technical eclecticism, which Lazarus subsequently formalized into multimodal therapy (Lazarus, 1981) made a great deal of sense to me. And I remember a wonderful little published paper by Lazarus, written during the height of the assertivenesstraining fad, about an encounter between himself and a surly salesperson. The moral of that story, for Lazarus, was that sometimes a compassionate rather than an assertive response is what is called for when one is confronted with hostility. I remember few things that anyone has ever said to me, yet I remember an offhand comment Lazarus made during a seminar I took with him in 1978: "The worst thing you can do to somebody is humiliate them.” This compassion pervaded all his work.

I was lucky, in 1970, to take a summer-school course in "behavior modification” with Nathan Azrin. What I learned from him in that course and from his published work afterwards (e.g., Azrin, 1977) is that successful therapy is effortful. You have to be thorough and attack a problem from several angles if you want to solve it. This has proven true over and over again in my own practice.

\section{Two Early-Career Learning Experiences: Family Therapy and Hypnosis}

Two specific early-career educational efforts were important to my development: a study group on family therapy, and my learning hypnosis. In 1978 after (working) a year in a state mental hospital, I got a job at a young and dynamic community mental health center. The center had hired many talented people, and I found myself among stimulating colleagues. I was in the outpatient Employment Assistance Program section of the center's alcohol treatment service and 
was called on to do a good deal of couple therapy. I didn't know anything about it, but looking around I realized that there were few people who did. I had my eye on going into private practice, and from a marketing standpoint it seemed advantageous to claim expertise in helping people with their marriages. I and four other people who were interested in couple and family therapy organized into a family-therapy study group. Every week we would read an article or book and then we'd discuss it over lunch on Friday. The group continued for about two years and we all learned a great deal-both from the readings and from discussing cases with each other. By the end of that time I felt a bit less like I was flying blind doing marital therapy. I continued reading intensively in that area, and by 1983 I was able to publish in it myself (Hamburg, 1983; Hamburg, 1985a; Hamburg, 1985b).

In 1986 I made a decision to change a personal habit. What surprised and mystified me was how effortless it was to make that decision. (I am still mystified.) I knew nothing about hypnosis but wondered if it could result in such effortless decisions to modify habits such as smoking. So I took an introductory weekend course in hypnosis and followed it up with an intermediate course taught by the very talented and knowledgeable expert in the hypnotherapy of pain, Joseph Barber. It was only after the course with Barber that I felt confident enough to try hypnosis with my own clients. Soon enough I found that, for me, it was of no use in helping clients with habit control, but that it was indispensible in all sorts of anxiety disorders, especially post-traumatic disorders, and in pain control (Hamburg, 2006).

I got licensed, and began private practice in October, 1980. The mechanics of how I practice now are, surprisingly perhaps, not very different from what they were then: return calls for service within a day; schedule the first appointment within a week; sessions last an hour, more or less-often more in couple therapy; take detailed in-session notes on a 4 x 6-inch scratch pad and reduce them to a prose narrative as soon as possible, but certainly within 24 hours; and at the start of each session, take the initiative in setting the agenda, based on the notes, and especially the homework assignments, of the previous session. The notes are the bedrock of my work. I cannot imagine doing therapy that has continuity and velocity without them.

Unless clients are in considerable distress, I initially schedule sessions every other week. If they are in distress, I will meet with them weekly, or more often, until the distress subsides. The interval between sessions is increased in accordance with improvement. Some clients continue with monthly sessions for some time-for years in two current cases. But most clients feel ready to quit therapy after just two or three monthly visits. In almost all cases, I initiate the termination. Clients return as new issues arise, occasionally after a lapse of many years. I have always carried a few long-term clients in my practice, divided about evenly between ones with insurance and ones, like the Guatemalan torture survivor who has been in my practice since 1996, whom I see pro bono. What they all have in common is chronic, severe psychopathology.

As scientific knowledge has accumulated, my views on a number of important issues have changed. For example, it now seems to me evident that temperament, personality, and psychopathology are much more a matter of inheritance than I would have liked to believe in my early behavioral days (Hamburg, 1998). 
S.R. Hamburg

Pragmatic Case Studies in Psychotherapy, http://pcsp.libraries.rutgers.edu

Volume 13, Module 4, Article 1, pp. 284-328, 02-24-18 [copyright by author]

\section{The Role of Failure and Clinical Mistakes}

But the biggest change in the way I think and work-how I approach couple therapywas the result not of scientific advance but clinical failure. My development in this area paralleled, but was independent of, that of two age-mates of mine, Andrew Christensen and Neil Jacobson. We all started out in the late 70s/early 80s, gung ho on helping couples change via behavioral techniques, using training in areas such as communication, negotiation, and problem solving.

This early enthusiasm was beaten out of us by the punishing contingencies of trying to work in that way. We came to realize that a couple's level of compatibility set a limit on how conflict-free and happy their marriage could be. For incompatible couples, the best that could be done was to help them be more accepting and tolerant of their differences. This conclusion led Christensen and Jacobson to craft an acceptance-based approach to couple therapy (Jacobson \& Christensen, 1996). It led me to formulate a compatibility-based theory of conjugal love in a book titled, Will Our Love Last? (Hamburg, 2000), in an attempt to help people marry compatible partners in the first place.

In retrospect, I am astonished at how long — about 15 years - I did marital therapy without an explicit theory of conjugal love, and at how many couple therapists still practice without one. Susan Johnson (2011) has made much of identifying conjugal love with attachment, but as I explain in Will Our Love Last, I believe that is mistaken and a source of painful confusion for many unhappily married people. I do believe that there are some understandings and skills that couples can acquire to have better-functioning marriages. For example, with practice and exposure, they can desensitize their fear of open conflict and learn not to abort their fights (Hamburg, 2012).

I had waited a relatively long time to start practice. It was four years after my doctorate and I had accumulated a decent amount of clinical experience. Yet, I look back on some of those early cases and I cringe. I would handle those situations so differently now. In part, it is because I think differently now, especially about couples. But mostly it's because I don't make as many mistakes now as I did before.

As I say to my trainees, there are three kinds of mistakes: (a) the ones you never realize are mistakes or realize too late to be able to correct them; (b) the ones you make and realize are mistakes soon enough to correct them, and; (c) the ones you realize are mistakes before you make them and so stop yourself from making them. I don't think we can ever abolish our mistakes, but I think that with experience and self-criticism we can shift an increasing proportion from category (a) to category (c), or at least to (b).

The mistakes I've made over the years are mostly of two types. The first type is perceptual-I've missed something, or misperceived something about my client or an interaction. I remember, with regret, a couple I treated unsuccessfully not so many years ago. In retrospect I realized that I had utterly misperceived the wife's personality and, as a result, misinterpreted the nature of the couple's underlying problem. 
S.R. Hamburg

Pragmatic Case Studies in Psychotherapy, http://pcsp.libraries.rutgers.edu

Volume 13, Module 4, Article 1, pp. 284-328, 02-24-18 [copyright by author]

The second type of mistake is when I've been reckless-been a little too bold in a suggestion, pushed a little too hard for rapid change, tried a new therapeutic tactic without thinking it through. The latter was the case with my suggestion of the mirror exercise to Margie, that she confront her physical self in a mirror (Mahoney, 1991), which backfired: she was so depressed the day after the mirror exercise that she couldn't go to work. I've always been something of a psychotherapeutic tinkerer: hear about a new tactic or gimmick and want to throw it against the wall and see if it sticks. I should have known that Margie was too fragile for the mirror exercise, but I really wanted to try it. I have always been good at self-criticism but have always had to work at self-restraint.

I have two consolations in the incident of the mirror exercise with Margie. The first is something that was once said by a musician I revere, Coleman Hawkins: "If you don't make mistakes, you aren’t really trying."

The second, and more important, consolation is my confidence that Margie knew that I was assigning the mirror task from a position of fellow-feeling rather than one of superiority. She knew it because I conveyed it - because that is what I believe, that is what I live. My own experience as a client imprinted me with an indelible awareness that I am fundamentally like Margie rather than unlike her. We both are trying to make the best of a bad situation, trying to get through a difficult and perplexing life with some sense of self-esteem and meaning. The only important difference between us is that my book learning and practical experience happen to put me in the role of helper. That's what made it so easy for me to sit on the floor and invite her to sit with me.

\section{How Hard You Try}

Finally, speaking of trying, some years ago the New Yorker magazine had an article by one of their medical correspondents, Atul Gawande, on the treatment of cystic fibrosis (Gawande, 2004). This genetically determined illness is now treated by a highly defined, operationally specific protocol that was developed by a doctor at a medical center in Minnesota. The protocol has been adopted at medical centers all over the country. Yet despite using the same protocol, the different centers have produced widely differing success rates. One of Gawande's conclusions was that the centers with the better outcomes just tried harder. I do believe that much of the outcome variance in the healing arts is a function of how hard the healers try. I feel myself still to be in search of effective psychotherapy. I think I have tried hard up to now. If I ever see myself not trying hard, I'll hang it up. 